Supporting information.

\title{
Comparison of bioorthogonally cross-linked hydrogels for in situ cell encapsulation
}

Henan Zhan, Heleen de Jong, Dennis W. P. M. Löwik ${ }^{*}$

Radboud University Nijmegen, Institute for Molecules and Materials, Heyendaalseweg 135, 6525 AJ Nijmegen, the Netherlands

E-mail:dennis.lowik@ru.nl 


\section{Content}
(A) Supporting notes
(B) Supplementary figures.
(C) Appendix 1 of mass spectrometry spectra of peptides.
(D) Appendix 2 of MALDI-TOF spectra of polymers.
(E) Appendix 3. ${ }^{1} \mathrm{H}$ NMR spectra of organic compounds
(F) Appendix 4. Cryo-SEM images of hydrogels 


\section{(A) Supporting notes}

Synthesis of peptides: The peptides were synthesized on $1.0 \mathrm{~g}$ 2-chloro-trityl resin using standard Fmoc solid-phase peptide synthesis (SPPS) protocols. In short the resin was swollen in dry dichloromethane (DCM) for 20 min prior to use. The resin was functionalized with the first amino acid in $1 \mathrm{~h}$ with 2.0 eq of the required amino acid and 2.2 eq of N, N-Diisopropylethylamine (DiPEA). This procedure was repeated after which capping took place with 2.2 eq DiPEA and 10\% (v/v) methanol in DCM. Deprotection of the Fmoc groups was carried out by treatment with piperidine in $\mathrm{N}$, N-dimethylformamide (DMF) (20\%, v/v, three times $6 \mathrm{~min}$ ). Subsequent couplings were performed with 3.0 eq of the required amino acid, 3.3 eq of N, N'-diidopropylcarbodiimide (DIPCDI) and 3.6 eq of N-hydroxybenzotriazole (HOBt) in DMF. After each coupling and deprotection step, a Kaiser test was performed to ensure completion of the reaction. ${ }^{[34]}$ In the final step for AzAcGly-Pro-Gln(Trt)-Gly-Ile-Ala-Gly-Gln(Trt)-Gly-OH and AzAc-Arg(Pbf)-Gly-Asp(OtBu)-Ser(tBu)-Gly-OH, 3.0 eq of a zido acetic acid was coupled using DIPCDI (3.3 eq) and HOBt (3.6 eq). The peptides were cleaved from the resin with a mixture of DCM, trifluoroethanol (TFE) and acetic acid (HOAc) (3:1:1) for $2 \mathrm{~h}$. After filtration the solvent was removed under reduced pressure and co-evaporated with chloroform. The peptides were obtained as white solids after lyophilization from dioxane and purified using preparative HPLC. 


\section{AzAc-Gly-Pro-Gln(Trt)-Gly-Ile-Ala-Gly-GIn(Trt)-Gly-OH}

LC-MS: $1351.92[\mathrm{M}+\mathrm{H}]{ }^{+}\left(\right.$calculated $\left.[\mathrm{M}+\mathrm{H}]{ }^{+}=1351.62\right), \mathrm{Rt}=27.69 \mathrm{~min}$

\section{Appendix 1}

\section{AzAc-Arg(Pbf)-Gly-Asp(OtBu)-Ser(tBu)-Gly-OH}

LC-MS: $938.64[\mathrm{M}+\mathrm{H}]^{+}\left(\right.$calculated $\left.[\mathrm{M}+\mathrm{H}]^{+}=938.06\right), \mathrm{Rt}=23.70$ min Appendix

Star-PEG-BCN (19)

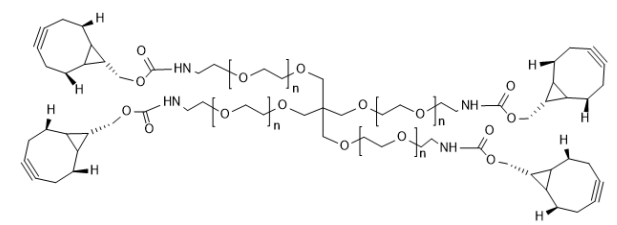

Figure S1. Title compound 19.
4-arm-PEG-amine (300 $\mathrm{mg}, 0.03 \mathrm{mmol})$, (1R,8S,9S)-bicyclo [6.1.0] non-4-yn-9-yl (50 $\mathrm{mg}, 0.18 \mathrm{mmol}), \mathrm{Et}_{3} \mathrm{~N}(50 \mu \mathrm{L}, 0.36 \mathrm{mmol})$

were dissolved in dry DCM $(10 \mathrm{~mL})$, and stirred o.n. at r.t. under nitrogen atmosphere. The reaction mixture was consecutively washed with $\mathrm{KHSO}_{4}$ and $\mathrm{NaOH}$, and dried over $\mathrm{MgSO}_{4}$. Subsequently, volatiles were removed under reduced pressure, and the crude mixture was purified using column chromatography (2-30\% $\mathrm{MeOH}$ in DCM), lyophilization from 1,4-dioxane yielded the polymer (200 mg, 62\%).

$\mathrm{R}_{\mathrm{f}}=0.31(10 \% \mathrm{MeOH}$ in DCM $)$

MALDI-TOF ( $\alpha$-cyano-4-hydroxycinnamic acid): Appendix 2.

${ }^{1} \mathrm{H}$ NMR (400 MHz, $\mathrm{CDCl}_{3}$ ) Appendix 3 


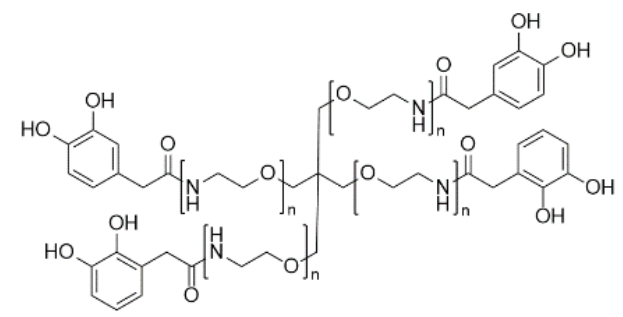

Figure S2. Title compound 20.

4-arm-PEG-amine (500 $\mathrm{mg}, 0.05 \mathrm{mmol})$, 3,4-dihydroxy phenylacetic acid (51 mg, 0.30 mmol), BOP (133 mg, $0.30 \mathrm{mmol})$, and DiPEA $(210 \mu \mathrm{L}, 1.23 \mathrm{mmol})$ were mixed in DMF $(14$ $\mathrm{mL}$ ), and stirred o.n. at r.t.. Next, DMF was removed under reduced pressure. The residue was dissolved in DCM, washed with $\mathrm{KHSO}_{4}$ and $\mathrm{NaOH}$. The organic layer was dried over $\mathrm{MgSO}_{4}$, and volatiles were removed under reduced pressure. The crude mixture was purified using column chromatography over basic aluminium oxide (10\% $\mathrm{MeOH}$ in DCM), lyophilization from 1,4-dioxane yielded the polymer (283 mg, 51\%).

$\mathrm{R}_{\mathrm{f}}=0.19(10 \% \mathrm{MeOH}$ in DCM $)$.

MALDI-TOF ( $\alpha$-cyano-4-hydroxycinnamic acid): Appendix 2.

${ }^{1} \mathrm{H}$ NMR (400 MHz, $\mathrm{CDCl}_{3}$ ) Appendix 3 


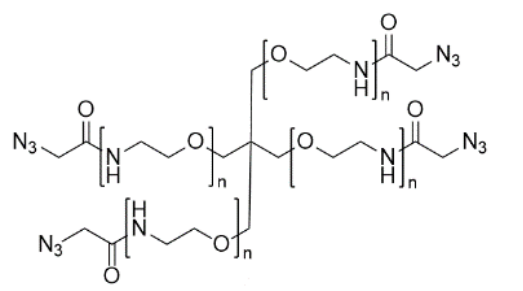

4-arm-PEG-amine (500 mg, $0.05 \mathrm{mmol}, 1$ equiv.), azidoacetic acid (40 $\mu \mathrm{L}, 0.40 \mathrm{mmol}, 8$ equiv.), BOP (177 mg, 0.40 mmol, 8 equiv.), and DiPEA (105 $\mu \mathrm{L}$,

Figure S3. Title compound 25. 0.60 mmol, 12 equiv.) were dissolved in DCM (20 $\mathrm{mL}$ ), and stirred at r.t. o.n.. The solution was washed with $\mathrm{KHSO}_{4}$ and brine, whereupon it was dried over $\mathrm{Na}_{2} \mathrm{SO}_{4}$. Volatiles were removed under reduced pressure, and the crude mixture was purified using column chromatography over aluminium oxide (10\% $\mathrm{MeOH}$ in DCM). Lyophilization from 1,4-dioxane yielded the polymer (321 mg, 59\%). For star-PEG-MMPcp- $\mathrm{N}_{3}$ and star-PEG-SDGR-N $\mathrm{N}_{3}$, just replace the azidoacetic acid for MMPcp and RGDS peptide sequences respectively. Other steps will be the same as the star-PEG-N 3 .

Star-PEG-N ${ }_{3}: R_{\mathrm{f}}=0.43(10 \% \mathrm{MeOH}$ in $\mathrm{DCM})$.

Star-PEG-MMPcp-N $\mathrm{N}_{3}: \mathrm{R}_{\mathrm{f}}=0.38$ (MeOH: DCM, 10:90)

Star-PEG-SDGR-N $3: \mathrm{R}_{\mathrm{f}}=0.38(\mathrm{MeOH}: \mathrm{DCM}, 10: 90)$

MALDI-TOF ( $\alpha$-cyano-4-hydroxycinnamic acid): Appendix 2.

${ }^{1} \mathrm{H} \mathrm{NMR}\left(400 \mathrm{MHz}, \mathrm{CDCl}_{3}\right)$ Appendix 3 


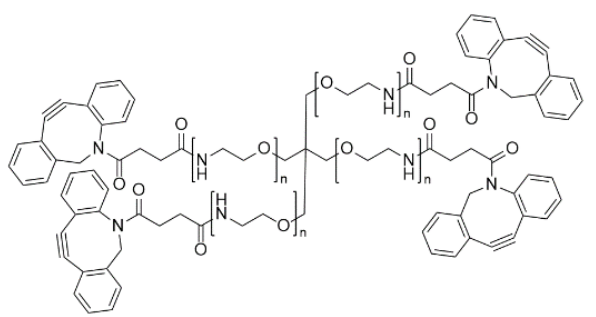

Figure S4. Title compound 21.
4-arm-PEG-amine (250 mg, $0.025 \mathrm{mmol}, 1$ equiv.),

Dibenzocyclooctyne-N-hydroxysuccinimidyl ester (65 mg, 0.16 mmol, 6 equiv.), and $\mathrm{Et}_{3} \mathrm{~N}$

(50 $\mu \mathrm{L}, 0.36 \mathrm{mmol}, 12$ equiv.) were dissolved in dry DCM (10 mL), and stirred o.n. under nitrogen atmosphere. The reaction mixture was consecutively washed with $\mathrm{KHSO}_{4}$ and brine, and dried over $\mathrm{MgSO}_{4}$. Subsequently, volatiles were removed under reduced pressure, and the crude mixture was purified using column chromatography (2-30\% MeOH in DCM), lyophilization from 1,4-dioxane yielded the polymer (157 mg, 56\%).

$\mathrm{R}_{\mathrm{f}}=0.26(10 \% \mathrm{MeOH}$ in DCM $)$.

MALDI-TOF ( $\alpha$-cyano-4-hydroxycinnamic acid): Appendix 2.

${ }^{1} \mathrm{H}$ NMR (400 MHz, $\mathrm{CDCl}_{3}$ ) Appendix 3

Star-PEG-Norbornene (23)

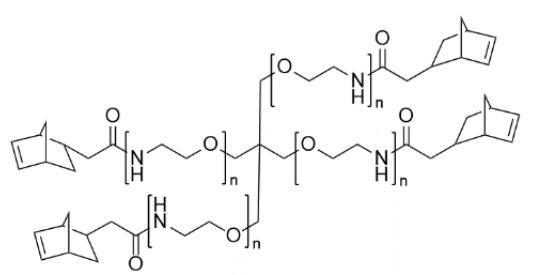

Figure S5. Title compound 23.
4-arm-PEG-amine (500 mg, $0.05 \mathrm{mmol}, 1$ equiv.), bicyclo[2.2.1]hept-5-ene-2-carboxylic acid (42 mg, 0.30 mmol, 6 equiv.), and BOP (133 mg, 0.30 mmol, 6 equiv.) were dissolved in DCM, and 
o.n. at r.t.. The solution was washed with $\mathrm{KHSO}_{4}$ and brine, and dried over $\mathrm{MgSO}_{4}$. The crude mixture was purified via column chromatography over aluminium oxide in (2\% $\mathrm{MeOH}$ in DCM), lyophilization from 1,4-dioxane yielded the polymer (332 $\mathrm{mg}$, $63 \%)$.

$\mathrm{R}_{\mathrm{f}}=0.31(10 \% \mathrm{MeOH}$ in DCM).

MALDI-TOF ( $\alpha$-cyano-4-hydroxycinnamic acid): Appendix 2.

${ }^{1} \mathrm{H}$ NMR (400 MHz, $\mathrm{CDCl}_{3}$ ) Appendix 3

(Z)-9-oxabicyclo[6.1.0]non-4-ene (10)

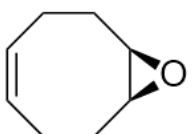

Figure S6. Title
A solution of 3-chloroperbenzoic acid (5.26 g, $30.47 \mathrm{mmol}, 1.1$ equiv.) in DCM was added dropwise to a suspension of $\mathrm{Na}_{2} \mathrm{CO}_{3} \quad(11.743$ g, 110.9 mmol, 4 equiv.), and

(1Z,5Z)-cycloocta-1,5-diene $\left(3.4 \mathrm{~mL}, 27.7 \mathrm{mmol}, 1\right.$ equiv.) in $\mathrm{DCM}$ at $0^{\circ} \mathrm{C}$. The mixture was allowed to warm to r.t. o.n.. Then, the mixture was filtered and washed with DCM. The combined organic phases were washed with brine, dried over $\mathrm{MgSO}_{4}$, and volatiles were removed under reduced pressure. The crude mixture was purified using column chromatography (5\% EtOAc in heptane) yielding the epoxide $(2.171 \mathrm{~g}$, $57 \%)$.

$\mathrm{R}_{\mathrm{f}}=0.25$ (5\% EtOAc in heptane).

${ }^{1} \mathrm{H}$ NMR (400 MHz, $\mathrm{CDCl}_{3}$ ) Appendix 3 


\section{(Z)-cyclooct-4-en-1-ol (11)}

$\mathrm{C}^{\mathrm{OH}}$

Figure S7. Title compound 11.
Epoxide 10 (1 g, $8 \mathrm{mmol}, 1$ equiv.) was slowly added to a suspension of $\mathrm{LiAlH}_{4}(910 \mathrm{mg}, 24 \mathrm{mmol}, 3$ equiv. $)$ in dry THF (33 mL). After the mixture had refluxed for $1.5 \mathrm{~h}$, it was cooled

to $0^{\circ} \mathrm{C}$. Consecutively $\mathrm{H}_{2} \mathrm{O}(1 \mathrm{~mL}), 15 \% \mathrm{NaOH}$ (aq, $\left.1 \mathrm{~mL}\right)$, and again $\mathrm{H}_{2} \mathrm{O}$ were added. The mixture was stirred at r.t. until the grey solid turned white. Next, celite and $\mathrm{MgSO}_{4}$ were added, this mixture was stirred for $30 \mathrm{~min}$. Solids were removed by filtration, and volatiles were removed using rotary evaporation, yielding the alcohol as a clear oil (891 mg, 88\%).

$\mathrm{R}_{\mathrm{f}}=0.51(30 \%$ EtOAc in heptane).

${ }^{1} \mathrm{H}$ NMR (400 MHz, $\left.\mathrm{CDCl}_{3}\right)$ Appendix 3

\section{(Z)-cyclooct-4-enyl-acetate (12)}<smiles>CC(=O)OC1CCC=CCCC1</smiles>

Figure S8. Title compound 12.
A solution of alcohol 11 (890 mg, $7.06 \mathrm{mmol}, 1$ equiv.), $\mathrm{Et}_{3} \mathrm{~N}$ (4.95 mL, 35 mmol, 5 equiv.), and 4-dimethylaminopyridine (40 $\mathrm{mg}, 0.33 \mathrm{mmol}, 0.05$ equiv. $)$ in dry DCM (15 mL) was mechanically stirred at $0^{\circ} \mathrm{C}$ for $15 \mathrm{~min}$. Then, acetic anhydride $(3 \mathrm{~mL}, 52.65 \mathrm{mmol}$, 7.5 equiv.) was added, and the mixture was allowed to warm to $21^{\circ} \mathrm{C}$ o.n.. When the reaction had finished, it was cooled to $0^{\circ} \mathrm{C}$ and quenched with $\mathrm{H}_{2} \mathrm{O}(8 \mathrm{~mL})$. The organic phase was washed with brine, dried over $\mathrm{Na}_{2} \mathrm{SO}_{4}$, and concentrated under reduced pressure. The product was purified using column chromatography (10\% 
EtOAc in heptane), yielding the acetate as a colourless oil (1.38 g, 74\%)

$\mathrm{R}_{\mathrm{f}}=0.33$ (10\% EtOAc in heptane).

${ }^{1} \mathrm{H}$ NMR (400 MHz, $\mathrm{CDCl}_{3}$ ) Appendix 3

\section{(E)-cyclooct-4-enyl-acetate (13)}

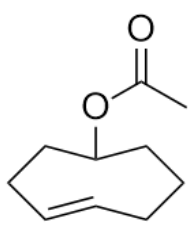

Figure S9. Title compound 12.
Upon rinsing the setup tubing (total V: $105 \mathrm{~mL}$, residence V: 100 $\mathrm{mL}$ ) with degassed $\mathrm{n}$-heptane, it was filled with a solution of cis-acetate 12 (1.1 g, $6.6 \mathrm{mmol}, 1$ equiv.) and methyl benzoate (177 mg, $1.3 \mathrm{mmol}, 0.2$ equiv.) in degassed n-heptane (100 mL).

A solution of silver nitrate (7.262 g, $42.75 \mathrm{mmol}, 4.5$ equiv.) in $0.1 \mathrm{mM}$ nitric acid (aq, $140 \mathrm{~mL}$ ) with degassed $\mathrm{n}$-heptane $(30 \mathrm{~mL})$ was added to the $100 \mathrm{~mL}$ CLLEM flask. The pump inlet was placed at the top of the organic phase, the pump outlet was placed in the aqueous phase, just above the stirring magnet. O.n., the organic phase was led repeatedly along a laser with a wavelength of $254 \mathrm{~nm}$, each rotation having an exposure time of 20 minutes.

After the cycle had been repeated numerous times o.n., the aqueous phase was separated and washed with n-heptane. Ammonium hydroxide $(12.7 \mathrm{~mL}, 171 \mathrm{mmol})$ and n-heptane (50\% in volume) were added to the aqueous layer. Next, the organic layer was separated, washed with $\mathrm{H}_{2} \mathrm{O}$, dried over $\mathrm{Na}_{2} \mathrm{SO}_{4}$, and concentrated under reduced pressure, yielding a colourless oil of a racemic mixture (636 mg, 57\%).

$\mathrm{R}_{\mathrm{f}}=0.67(50 \%$ EtOAc in heptane). 
${ }^{1} \mathrm{H}$ NMR (400 MHz, $\mathrm{CDCl}_{3}$ ) Appendix 3

(E)-cyclooct-4-enol (14)

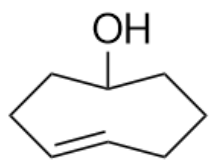

Figure S10. Title

compound 14.
Acetate 13 (564 mg, $3.35 \mathrm{mmol}, 1$ equiv.) was dissolved in 1,4-dioxane $(10 \mathrm{~mL}), 1 \mathrm{M} \mathrm{NaOH}(33.5 \mathrm{~mL}, 33.5 \mathrm{mmol}, 10$ equiv.) was added, and the mixture was stirred o.n.. When the

reaction had finished (TLC), the 1,4-dioxane was removed under reduced pressure, and DCM was added (10 mL). The organic layer was washed with brine, dried over $\mathrm{MgSO}_{4}$, and concentrated under reduced pressure, yielding a colourless oil of a racemic mixture of the product $(380 \mathrm{mg}, 90 \%)$.

$\mathrm{R}_{\mathrm{f}}=0.5,0.33(50 \%$ EtOAc in heptane).

${ }^{1} \mathrm{H}$ NMR (400 MHz, $\mathrm{CDCl}_{3}$ ) Appendix 3

(E)-cyclooct-4-enyl-(4-nitrophenyl)carbonate (15)

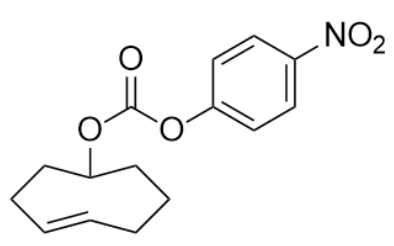

Figure S11. Title compound 15.
Alcohol 14 (92 mg, $0.55 \mathrm{mmol})$ was dissolved in dry DCM $(10 \mathrm{~mL})$ and pyridine $(129 \mu \mathrm{L}, 1.37 \mathrm{mmol}, 2.5$ equiv.) was added. Hereto, a solution of 4-nitrophenylchloroformate (121 mg, $0.6 \mathrm{mmol}, 1.1$ equiv.) in dry DCM ( $2 \mathrm{~mL})$ was added, and the mixture was stirred at r.t. for 30 minutes. The layers were separated after addition of $\mathrm{NH}_{4} \mathrm{Cl}(1 \mathrm{M}$, aq). Upon extraction of the aqueous layer with DCM, the organic layers were dried over $\mathrm{MgSO}_{4}$ and concentrated under reduced pressure. The crude mixture was purified using column 
chromatography (5\% EtOAc in heptane) yielding the carbonate (149 mg, 93\%).

$\mathrm{R}_{\mathrm{f}}=0.29$ (10\% EtOAc in heptane).

${ }^{1} \mathrm{H}$ NMR (400 MHz, $\mathrm{CDCl}_{3}$ ) Appendix 3

\section{Star-PEG-TCO (17)}

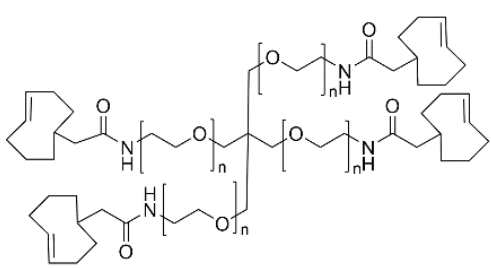

4-star-PEG-amine (225 mg, $0.0225 \mathrm{mmol}, 1$ equiv.) and carbonate 15 (40 mg, $0.14 \mathrm{mmol}, 6$ equiv.) were dissolved in dry DMF (10 mL). $\mathrm{Et}_{3} \mathrm{~N}$

Figure S12. Title compound 17.

(77 $\mu \mathrm{L}, 0.55 \mathrm{mmol}, 24.6$ equiv.) was added, and the reaction was stirred for $24 \mathrm{~h}$. When the reaction had finished, the reaction mixture was diluted with water. This mixture was acidified with $6 \%$ acetic acid and extracted with DCM. The organic layers were washed with water, dried over $\mathrm{MgSO}_{4}$ and concentrated in vacuo. The crude mixture was purified using column chromatography (10-50\% $\mathrm{MeOH}$ in DCM). Lyophilization from water yielded the polymer (50 mg, $21 \%)$.

$\mathrm{R}_{\mathrm{f}}=0.46(10 \% \mathrm{MeOH}$ in DCM $)$.

${ }^{1} \mathrm{H}$ NMR (400 MHz, $\mathrm{CDCl}_{3}$ ) Appendix 3 
<smiles>Cc1nnc(-c2ccc(CC(=O)O)cc2)nn1</smiles>

Figure S13. Title compound 20. 2-(4-cyanophenyl)acetic acid (830 $\mathrm{mg}, 5.15 \mathrm{mmol})$ and $\mathrm{Zn}(\mathrm{OTf})_{2}(914 \mathrm{mg}, 2.15 \mathrm{mmol}, 0.5$ equiv.) were dissolved in 1,4-dioxane $(4 \mathrm{~mL})$, and acetonitrile $(2.6 \mathrm{~mL}, 49.64$ mmol, 9.6 equiv.) was added. Hydrazine hydrate $(12 \mathrm{~mL}$,

248.20 mmol, 48 equiv.) was added dropwise; this solution was stirred o.n. at $60^{\circ} \mathrm{C}$.

The reaction was cooled to r.t., after which a mixture of $\mathrm{NaNO}_{2}(6.88 \mathrm{~g}, 100 \mathrm{mmol})$ in $\mathrm{H}_{2} \mathrm{O}(50 \mathrm{~mL})$ was added. Next, $\mathrm{HCl}(4 \mathrm{M})$ was added, until the solution turned red, gas evolution stopped and $\mathrm{pH}=1$. The reaction mixture was extracted with EtOAc, the combined organic layers were washed with brine, dried over $\mathrm{Na}_{2} \mathrm{SO}_{4}$ and concentrated in vacuo, yielding the tetrazine as pink solid $(1.03 \mathrm{~g}, 87 \%)$.

$\mathrm{R}_{\mathrm{f}}=0.38(10 \% \mathrm{MeOH}$ in DCM $)$.

${ }^{1} \mathrm{H}$ NMR (400 MHz, $\mathrm{CDCl}_{3}$ ) Appendix 3

Star-PEG-(4-(6-methyl-1,2,4,5-tetrazin-3-yl)phenyl (18)

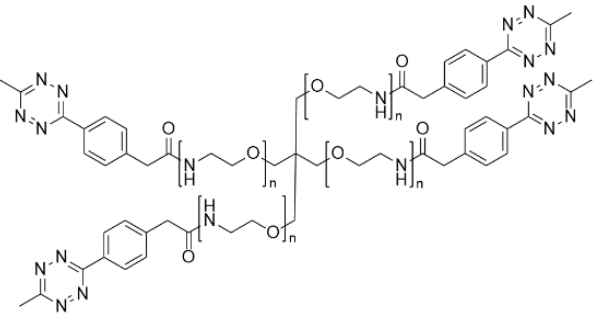

Figure S14. Title compound 18.
4-arm-PEG-amine (500 mg, $0.05 \mathrm{mmol}, 1$ equiv.), tetrazine 8 (69 $\mathrm{mg}, 0.30 \mathrm{mmol}, 6$ equiv.), and BOP (133 $\mathrm{mg}, 0.30 \mathrm{mmol}, 6$ equiv.) were dissolved in DMF (20 mL). DiPEA (210 $\mu \mathrm{L}, 1.23 \mathrm{mmol}, 24.6$ equiv.) was added, and the reaction mixture was stirred for o.n.. When the reaction had finished, DMF was removed under reduced 
pressure. The residue was dissolved in DCM, and subsequently washed with $\mathrm{KHSO}_{4}$ (1 M) and brine. The organic layer was dried over $\mathrm{MgSO}_{4}$, after which volatiles were removed under reduced pressure. The crude mixture was purified using column chromatography (10-20\% $\mathrm{MeOH}$ in DCM), lyophilization from dioxane yielded the polymer (250 mg, 46\%).

$\mathrm{R}_{\mathrm{f}}=0.25(10 \% \mathrm{MeOH}$ in $\mathrm{DCM})$.

${ }^{1} \mathrm{H}$ NMR (400 MHz, $\mathrm{CDCl}_{3}$ ) Appendix 3 
(B) Supplementary figures.<smiles>N#Cc1ccc(CC(=O)O)cc1</smiles>

7

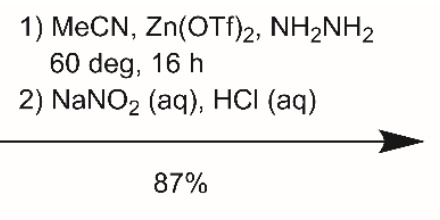

Scheme S1. One-pot two-step synthesis of 2-(4-(6-methyl-1,2,4,5-tetrazin-3-yl)<smiles>Cc1nnc(-c2ccc(CC(=O)O)cc2)nn1</smiles>

8 phenyl) acetic acid $\mathbf{8}$ from 2-(4-cyanophenyl) acetic acid 7.

A)

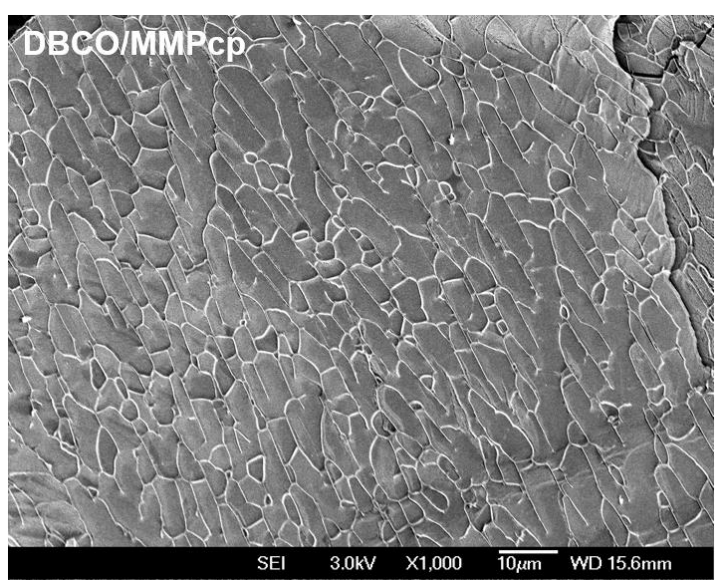

B)

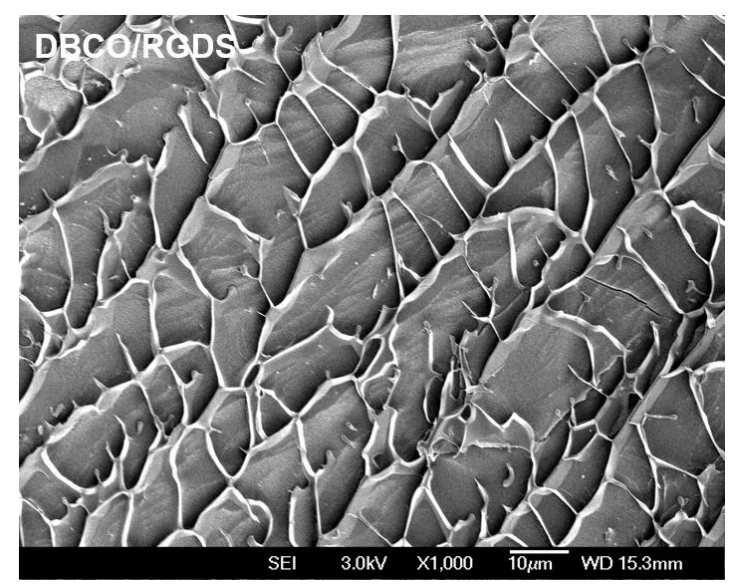

Figure S15. Cryo-SEM images of different hydrogel systems at a concentration of 20 mg/mL. A) DBCO/MMPcp gel, B) DBCO/RGDS gel. The scale bars represent 10 $\mu \mathrm{m}$. 
Table S1. Storage modulus (G'), loss modulus (G') and gelation point in minutes of different hydrogels. Values of the moduli are those recorded after 1h. All measurements were performed in triplo.

\begin{tabular}{|c|c|c|c|}
\hline Type of hydrogel & $\mathbf{G}^{\prime}(\mathbf{P a})$ & G”(Pa) & stable point(min) \\
\hline (A) TCO/Tet & $74 \pm 8$ & $2 \pm 3$ & $<1$ \\
\hline (B) $\mathrm{BCN} / \mathrm{DHPA}$ & $272 \pm 88$ & $14 \pm 13$ & $<1$ \\
\hline (C) BCN/Tet & $348 \pm 53$ & $43 \pm 15$ & $1.6 \pm 0.4$ \\
\hline (D) DBCO/DHPA & $968 \pm 104$ & $34 \pm 14$ & $45.6 \pm 13.5$ \\
\hline (E) $\mathrm{DBCO} / \mathrm{N}_{3}$ & $1163 \pm 76$ & $71 \pm 17$ & $56.6 \pm 7.3$ \\
\hline (F) DBCO/MMPcp & $1618 \pm 323$ & $48 \pm 11$ & $51.0 \pm 6.2$ \\
\hline (G) DBCO/RGDS & $1205 \pm 306$ & $49 \pm 4$ & $67.0 \pm 6.9$ \\
\hline (H) $\mathrm{BCN} / \mathrm{N}_{3}$ & $933 \pm 101$ & $51 \pm 32$ & $84.2 \pm 17.4$ \\
\hline (I) Nor/Tet & $1169 \pm 127$ & $61 \pm 46$ & $388.6 \pm 55.4$ \\
\hline
\end{tabular}



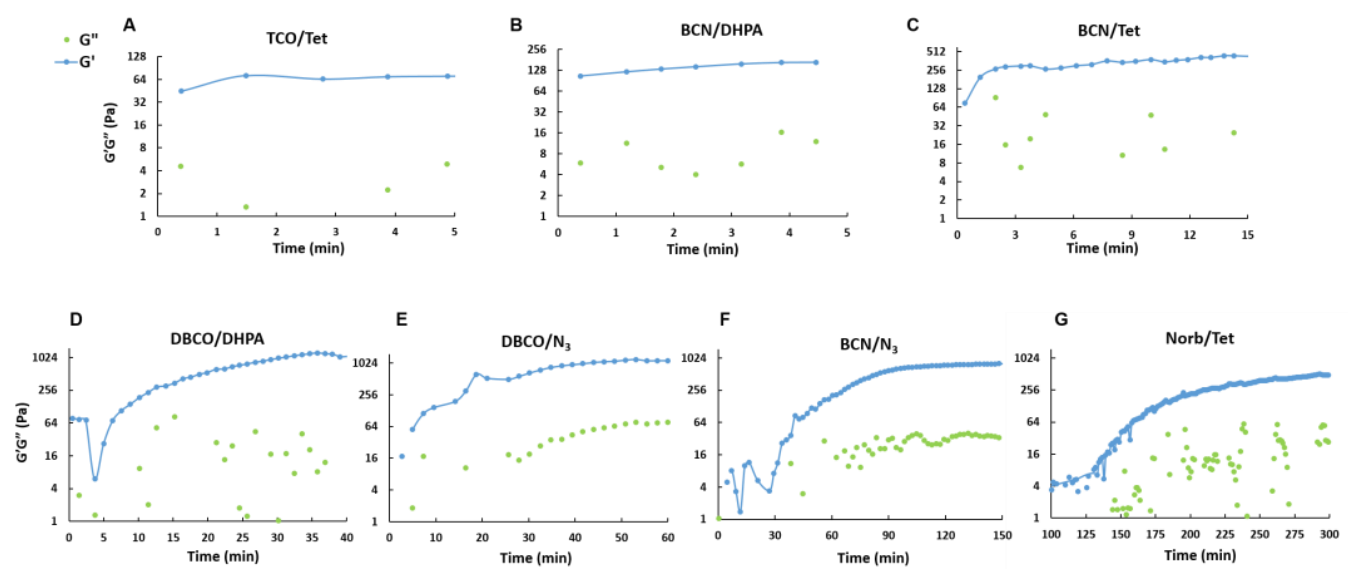

Figure S16 Gel properties described by rheology measurements at $37^{\circ} \mathrm{C}, 20 \mathrm{mg} / \mathrm{mL}$. A) $\mathrm{TCO} / \mathrm{Tet}, \mathrm{B}) \mathrm{BCN} / \mathrm{DHPA}$, C) $\mathrm{BCN} / \mathrm{Tet}, \mathrm{D}) \mathrm{DBCO} / \mathrm{DHPA}, \mathrm{E}) \mathrm{DBCO} / \mathrm{N}_{3}, \mathrm{~F}$ ) $\mathrm{BCD} / \mathrm{N}_{3}, \mathrm{G}$ ) Norb/Tet based PEG hydrogels. G' (in blue) stands for storage modulus and G' (in green) stands for loss modulus.

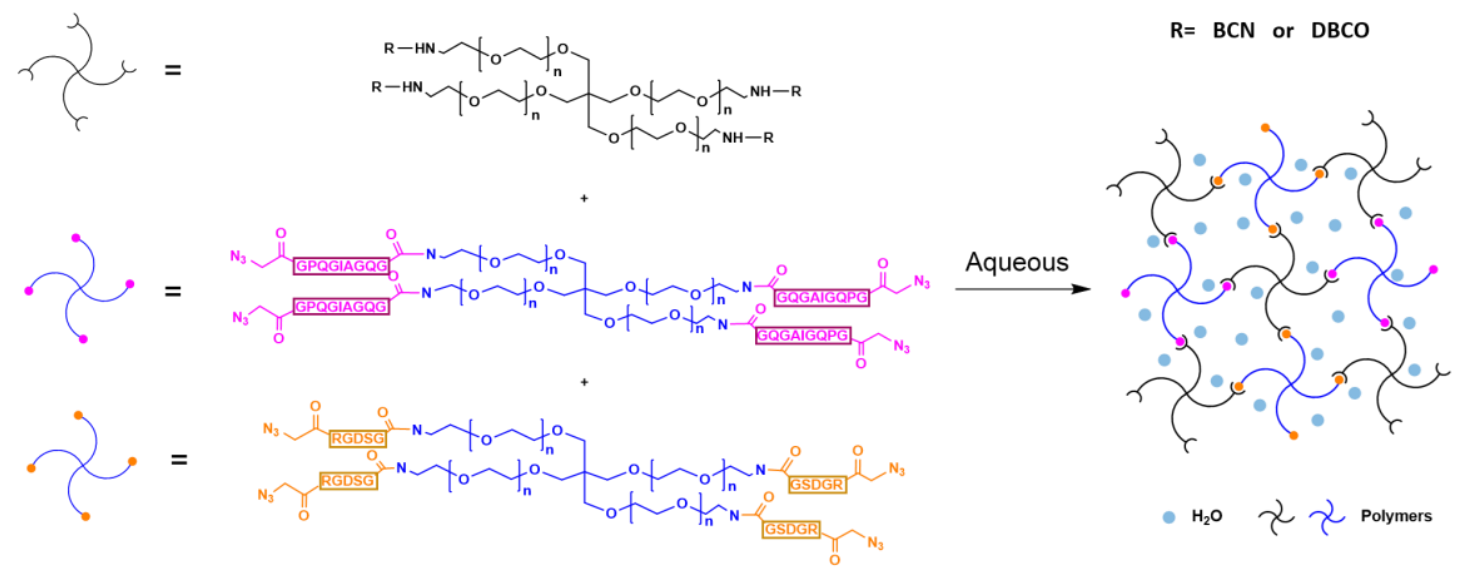

Figure S17. Schematic overview of incorporation of RGDS- and MMP- peptide motifs in $\mathrm{BCN} / \mathrm{N}_{3}$ and $\mathrm{DBCO} / \mathrm{N}_{3}$ hydrogel-structures. 
(C) Appendix 1. Mass spectrometry spectra of peptides

\section{AzAc-Gly-Pro-GIn(Trt)-Gly-Ile-Ala-Gly-Gln(Trt)-Gly-OH (MMPcp)}

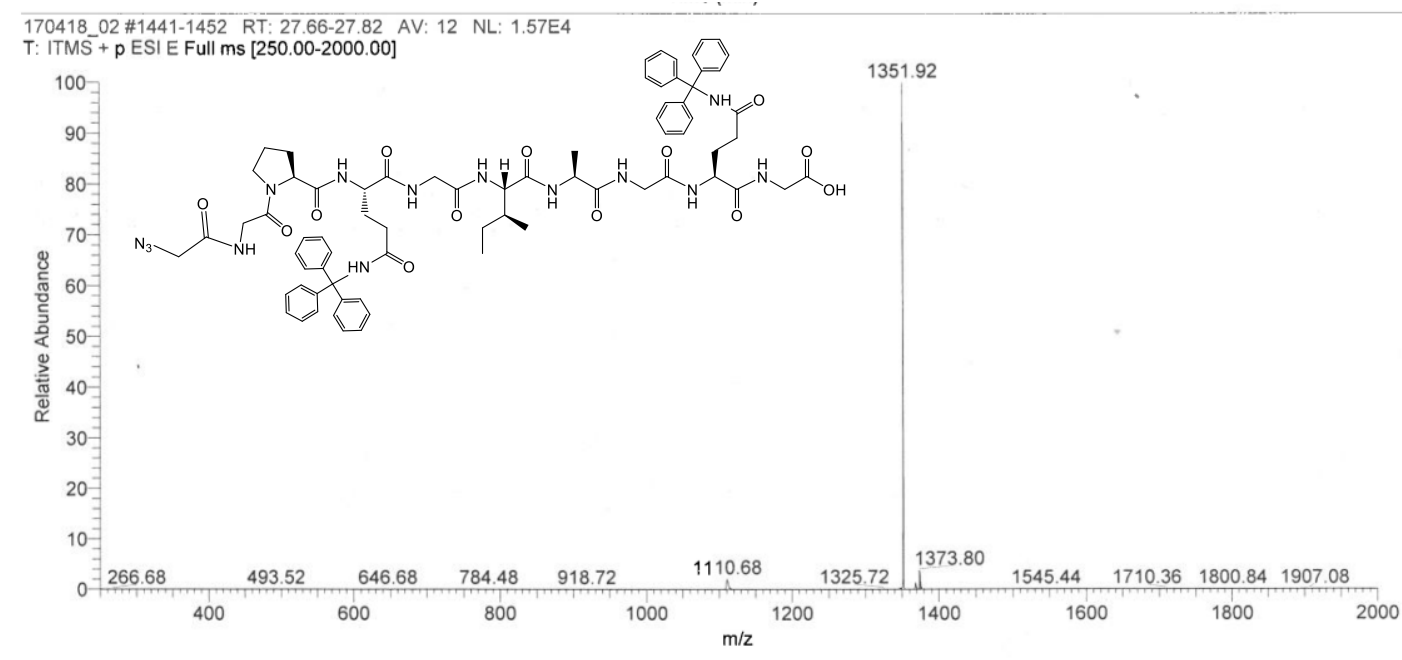

Figure S18. Mass spectrum of title compound.

\section{AzAc-Arg(Pbf)-Gly-Asp(OtBu)-Ser(tBu)-Gly-OH (RGDS)}

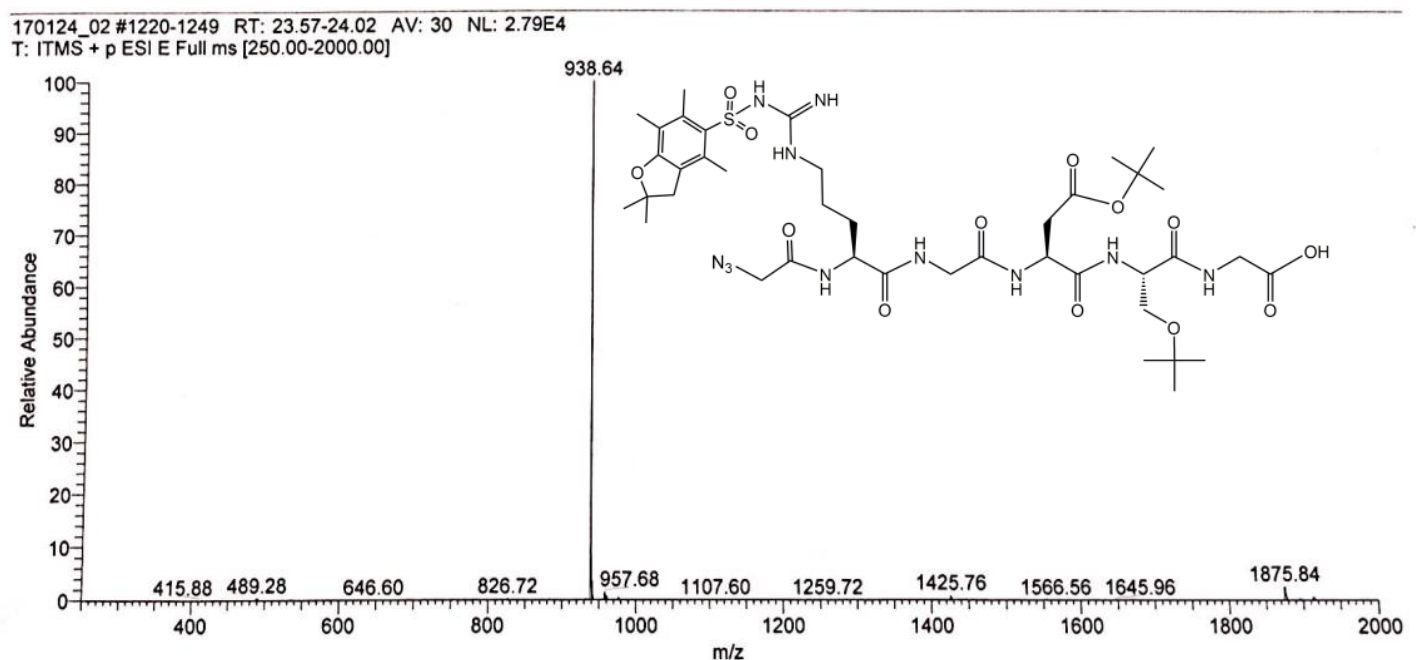

Figure S19. Mass spectrum of title compound. 
(D) Appendix 2. MALDI-TOF spectra of polymers

Star-PEG-TCO (17)

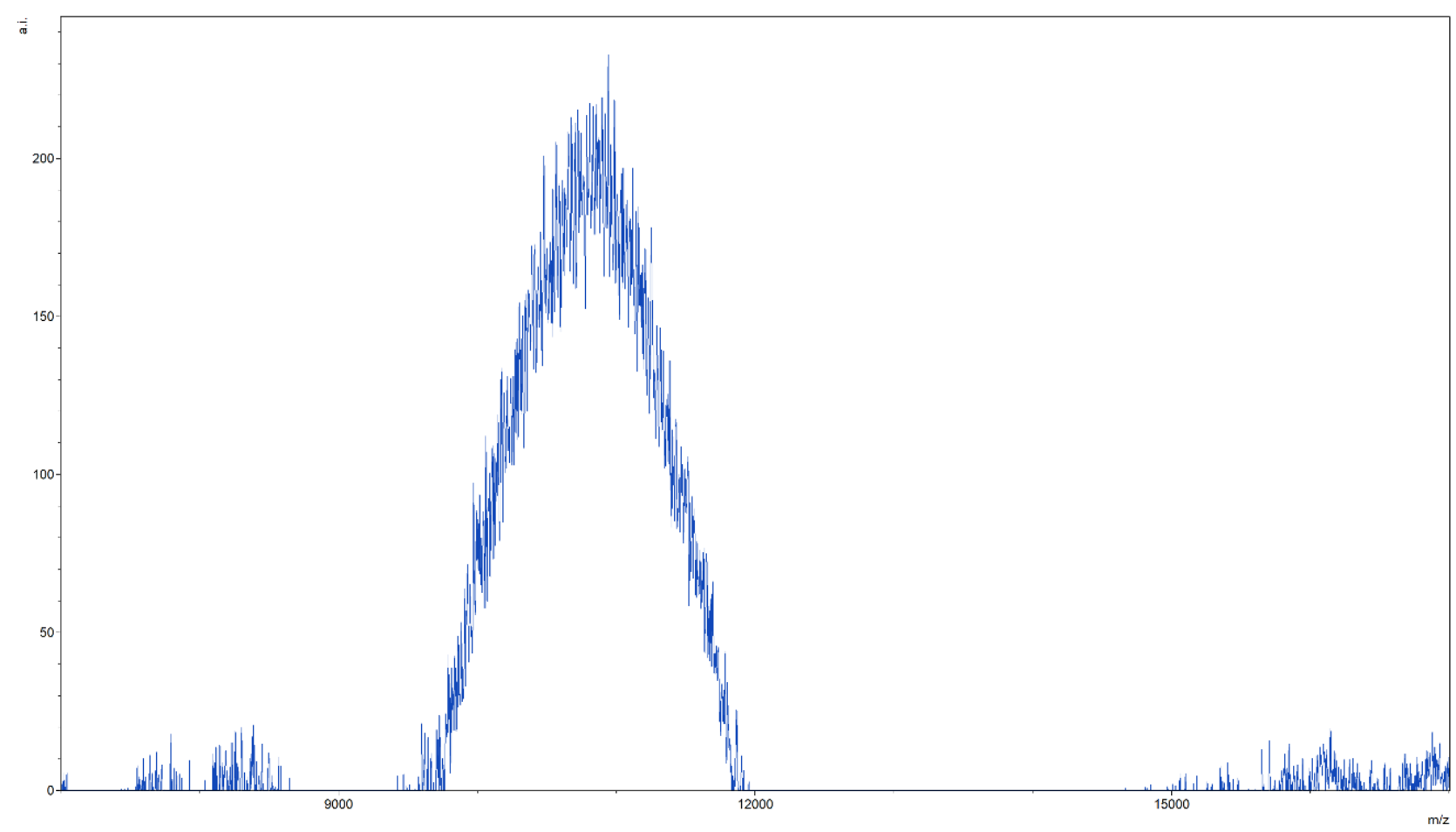

Figure S20. Mass spectrum of title compound. (Calculated m/z: 10596 for 220 ethylene glycol units) 


\section{Star-PEG-Tet (18)}

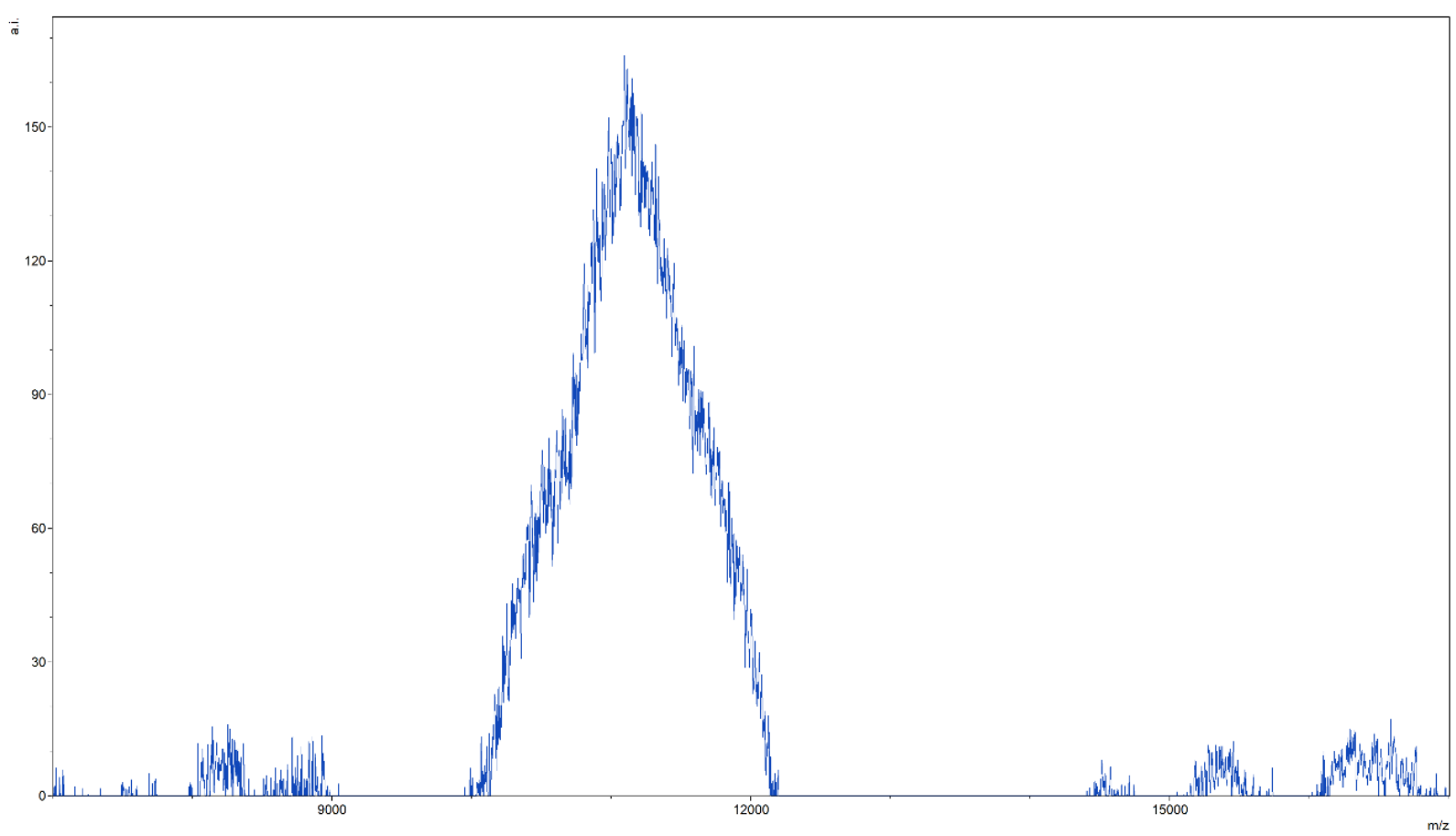

Figure S21. Mass spectrum of title compound. (Calculated m/z: 10836 for 220 ethylene glycol units)

\section{Star-PEG-BCN (19)}

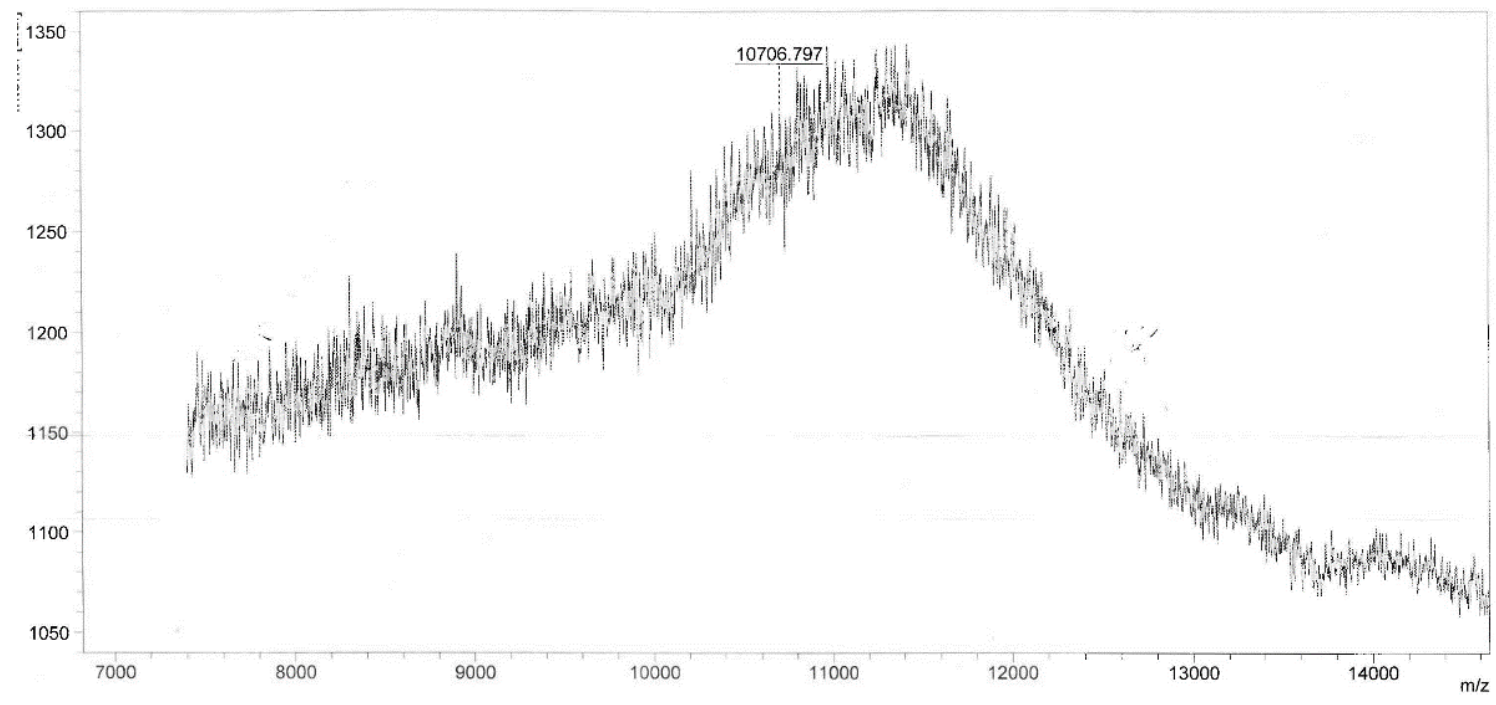

Figure S22. Mass spectrum of title compound. (Calculated m/z: 10692 for 220 ethylene glycol units) 


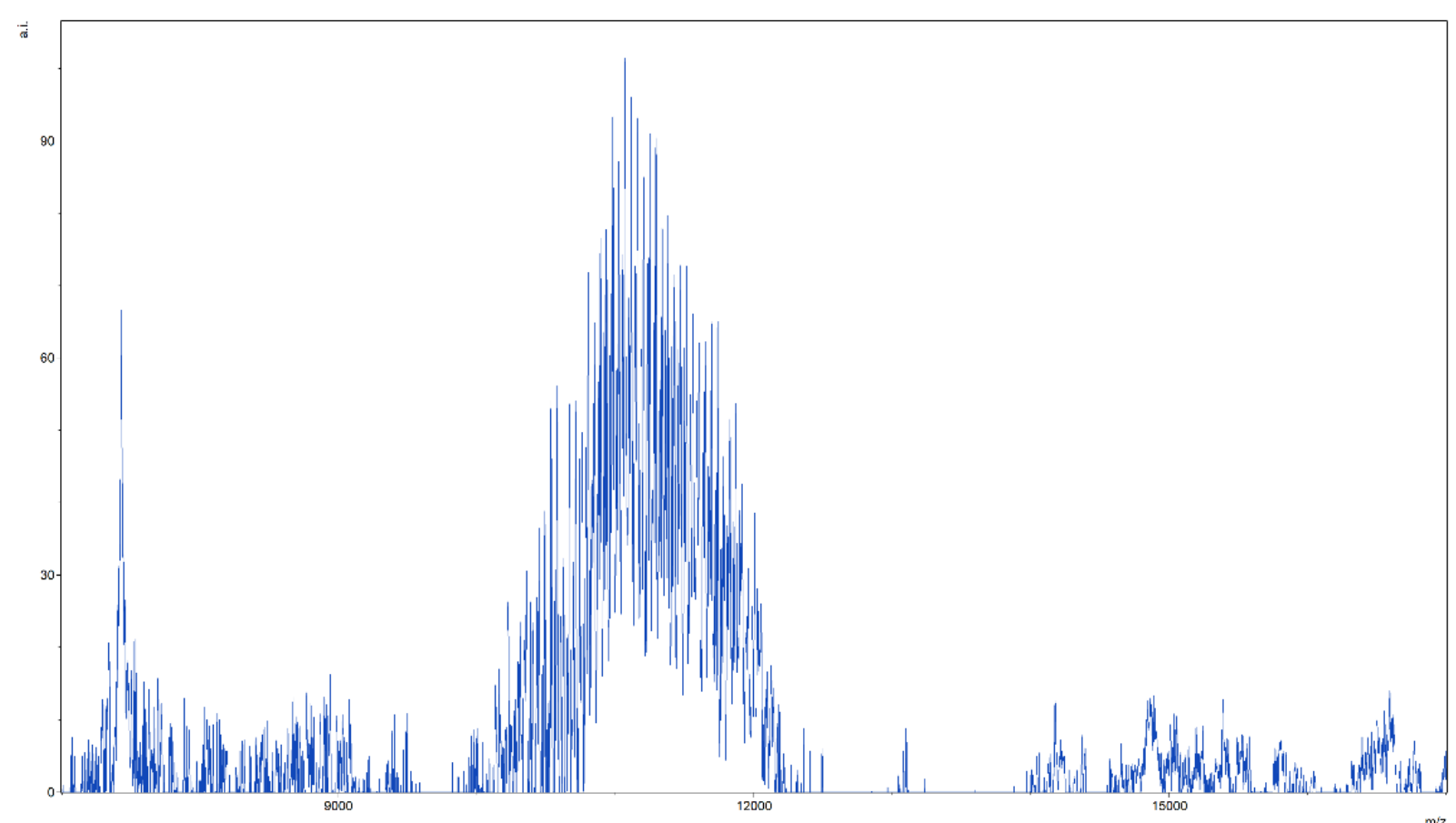

Figure S23. Mass spectrum of title compound. (Calculated m/z: 10588 for 220 ethylene glycol units)

Star-PEG-DBCO (21)

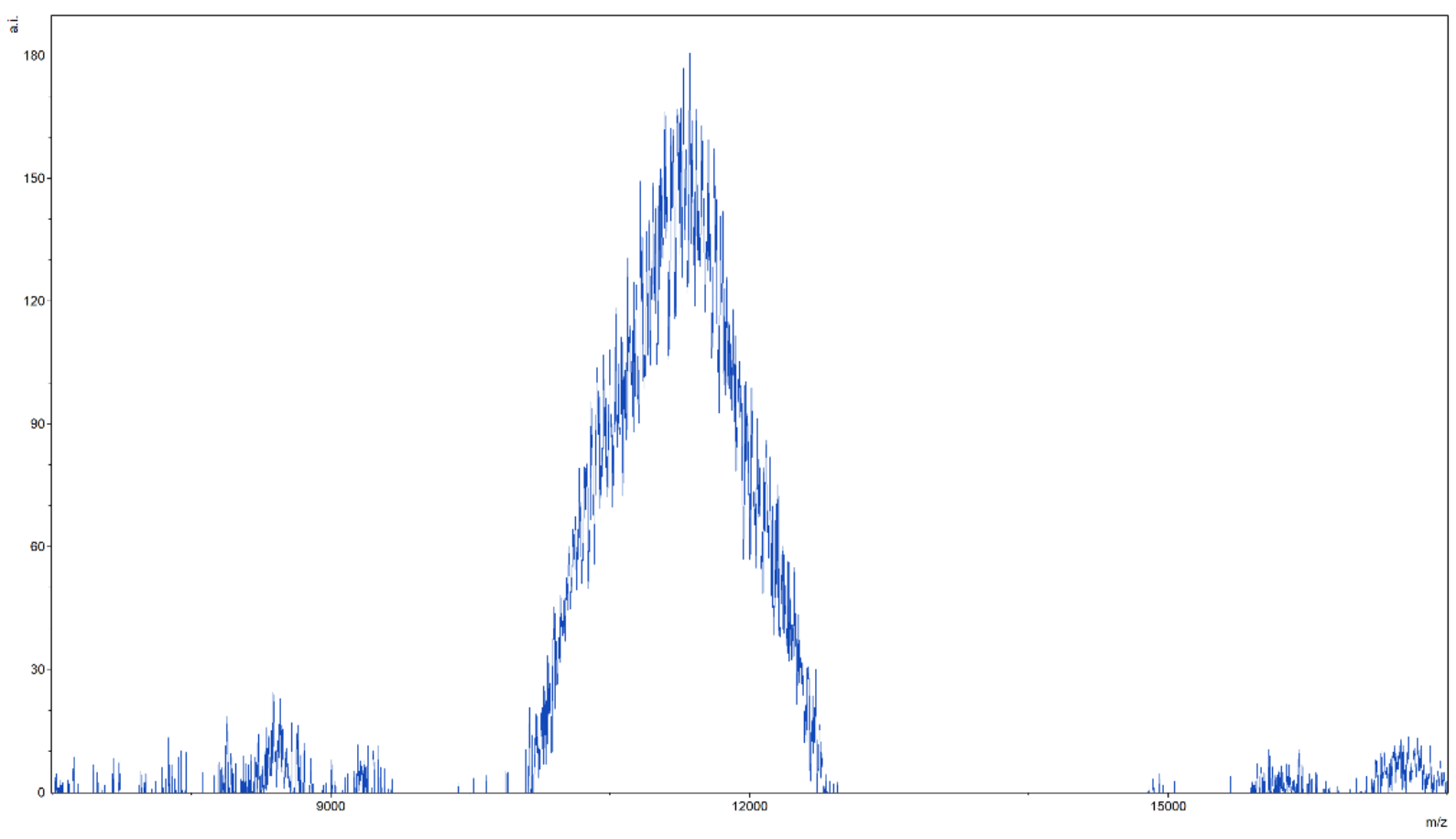

Figure S24. Mass spectrum of title compound. (Calculated m/z: 11136 for 220 ethylene glycol units) 
Star-PEG-N $N_{3}(22)$

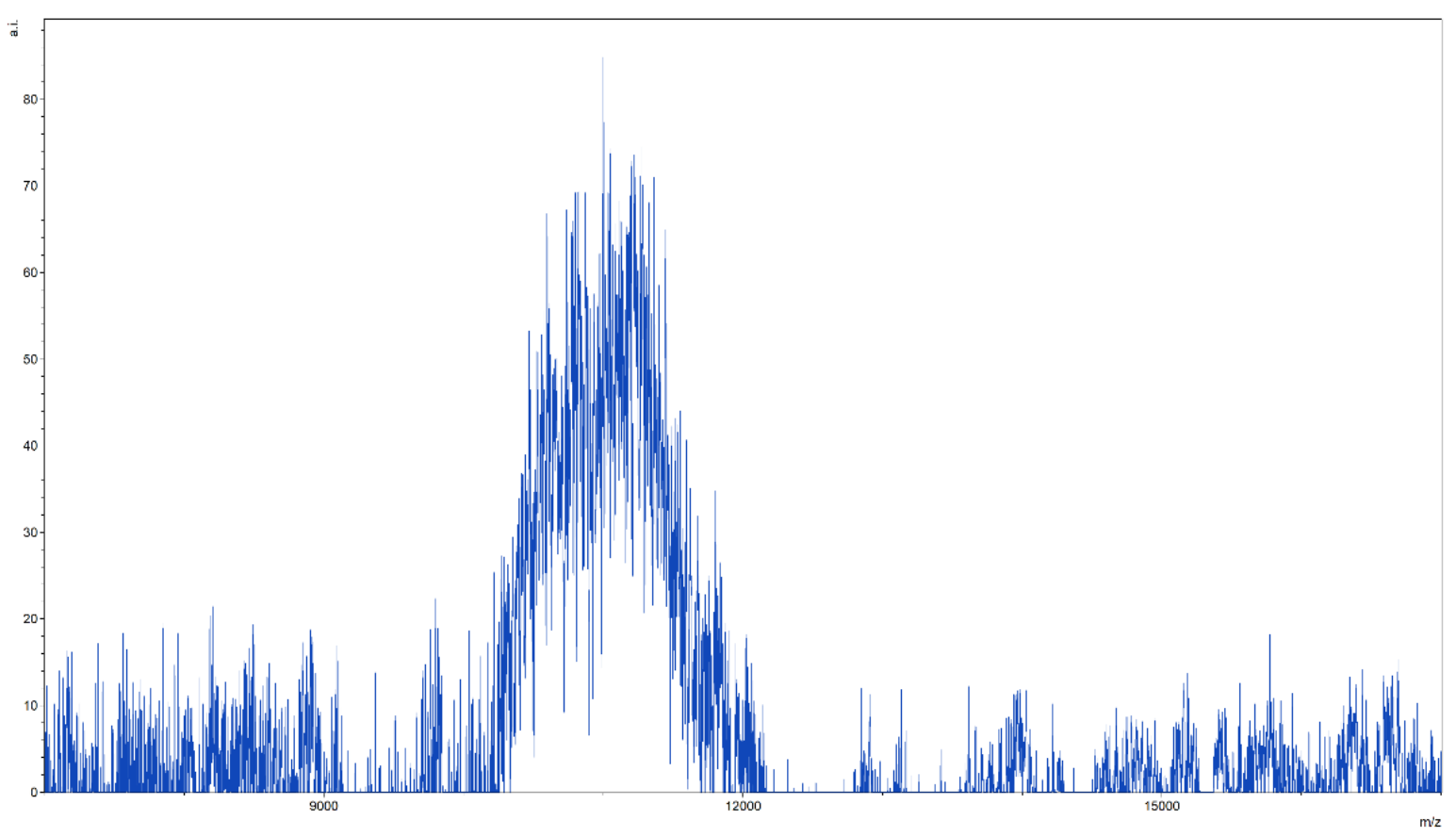

Figure S25. Mass spectrum of title compound. (Calculated m/z: 10320 for 220 ethylene glycol units)

Star-PEG-Norb (23)

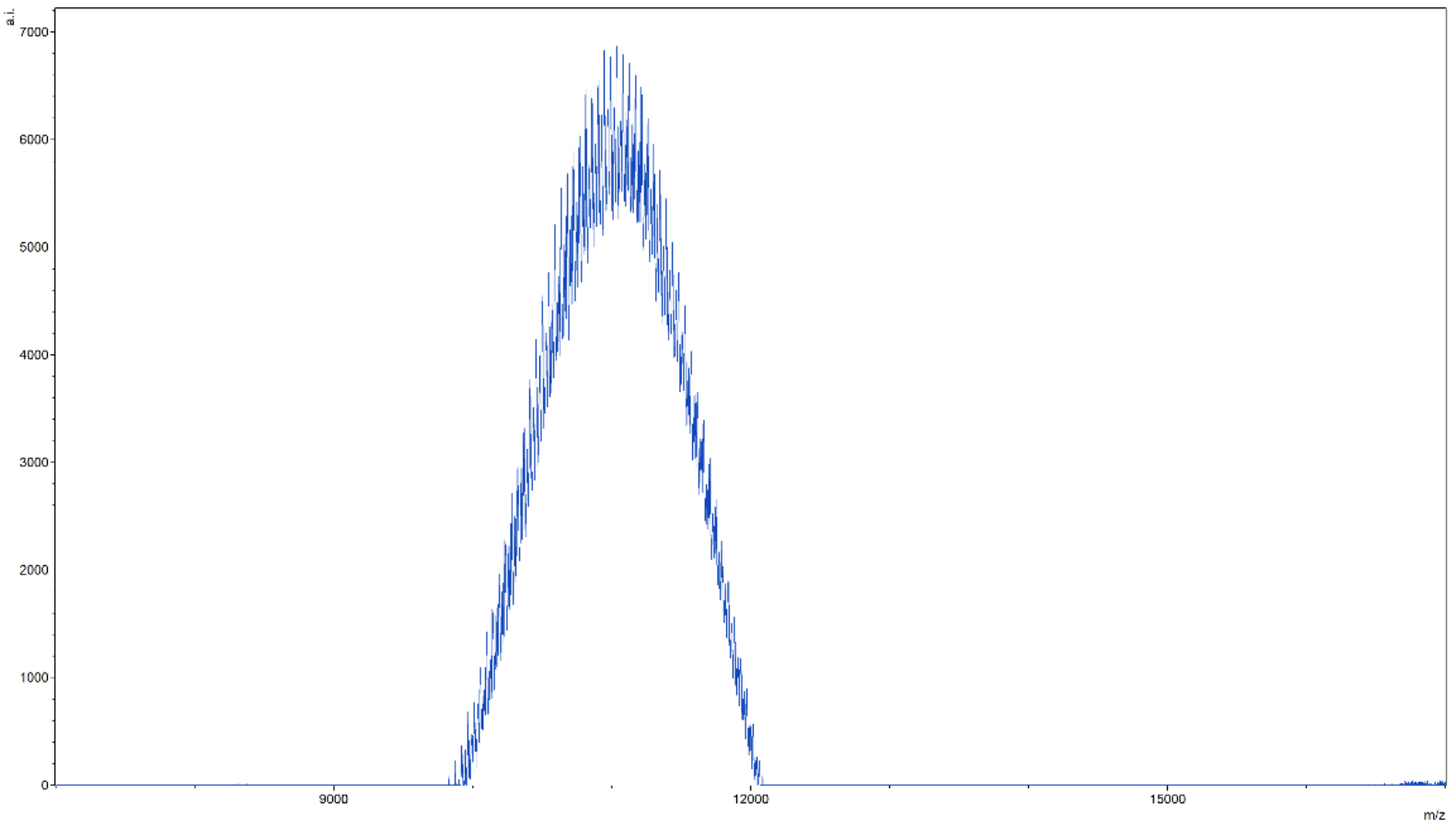

Figure S26. Mass spectrum of title compound. (Calculated m/z: 10524 for 220 ethylene glycol units) 
Star-PEG-MMPcp- $N_{3}(24)$

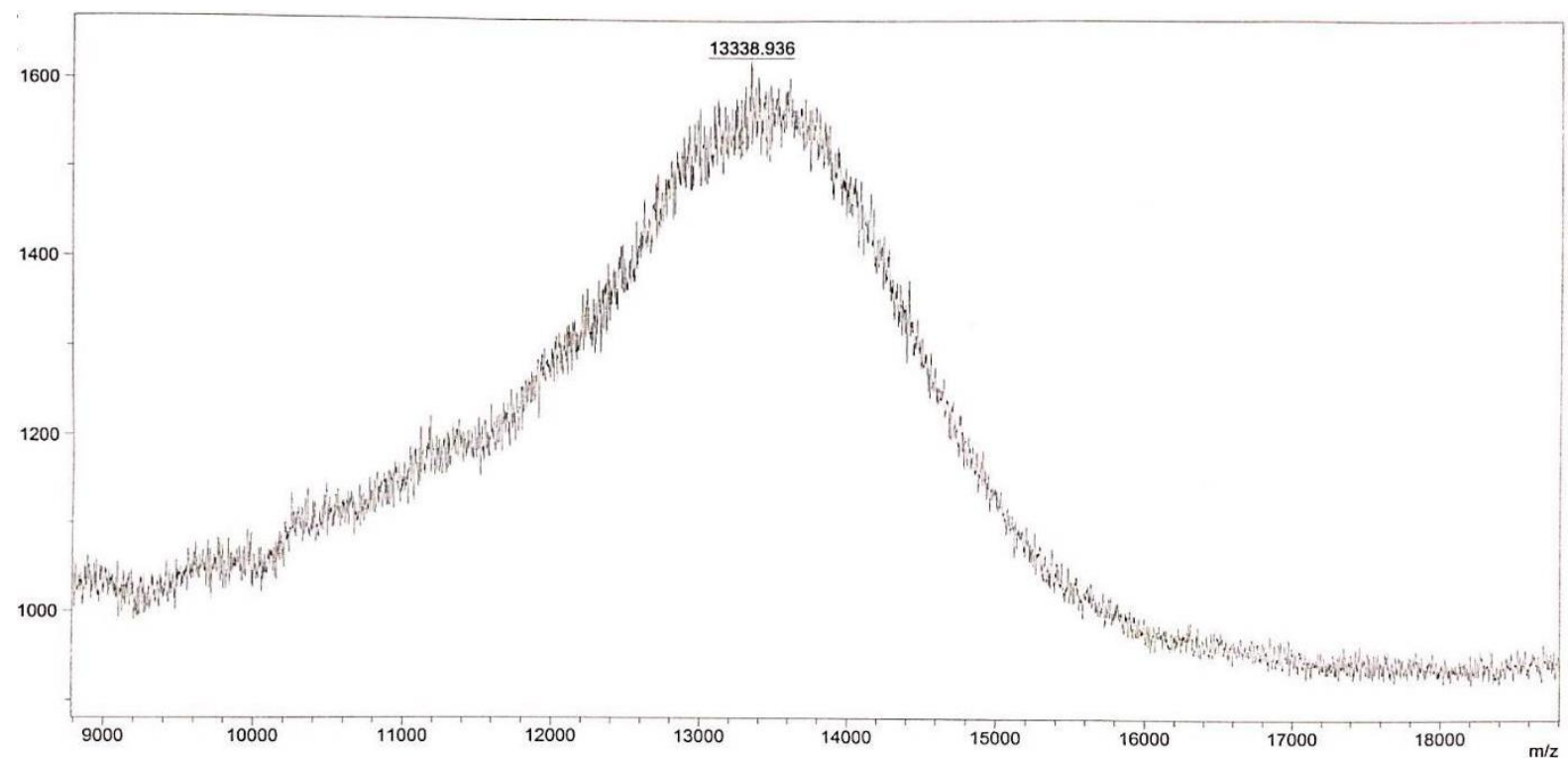

Figure S27. Mass spectrum of title compound. (Calculated m/z: 13380 for 220 ethylene glycol units)

\section{Star-PEG-SDGR-N $3(25)$}

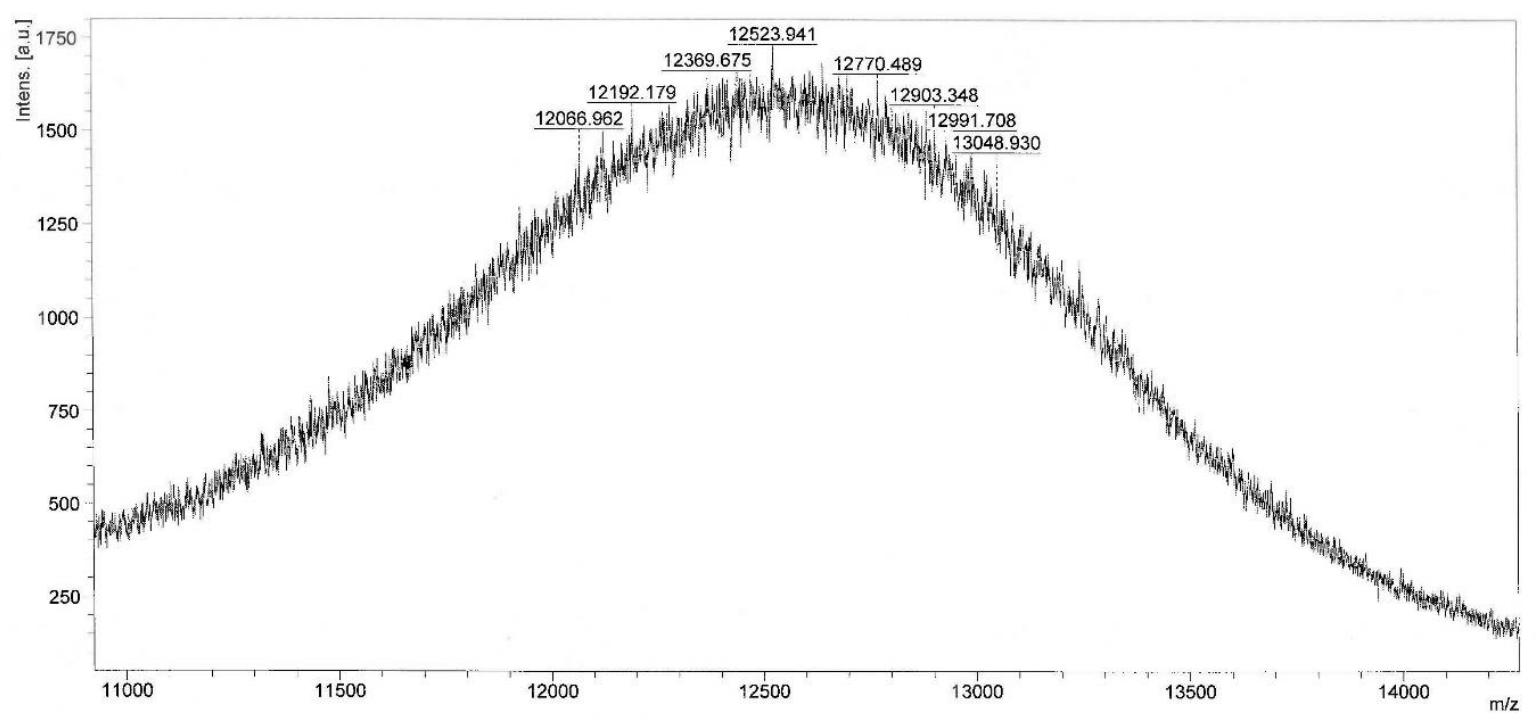

Figure S28. Mass spectrum of title compound. (Calculated m/z: 12208 for 220 ethylene glycol units) 
(E) Appendix 3. ${ }^{1} \mathrm{H}$ NMR spectra of organic compounds

2-(4-(6-methyl-1,2,4,5-tetrazin-3-yl)phenyl)acetic acid (Tet) (8)

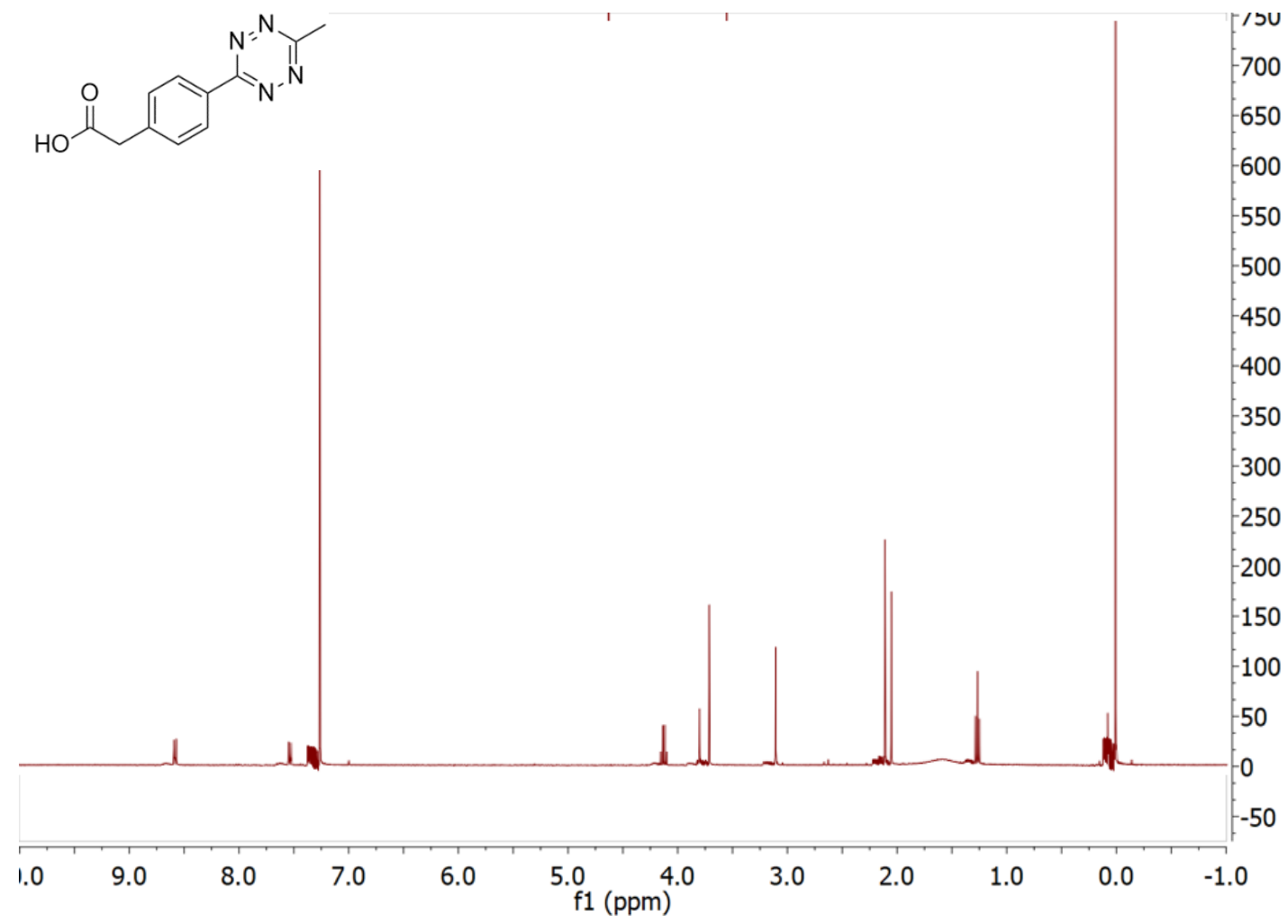

Figure S29. ${ }^{1} \mathrm{H}-\mathrm{NMR}$ spectrum of title compound. 
(Z)-9-oxabicyclo[6.1.0]non-4-ene (10)

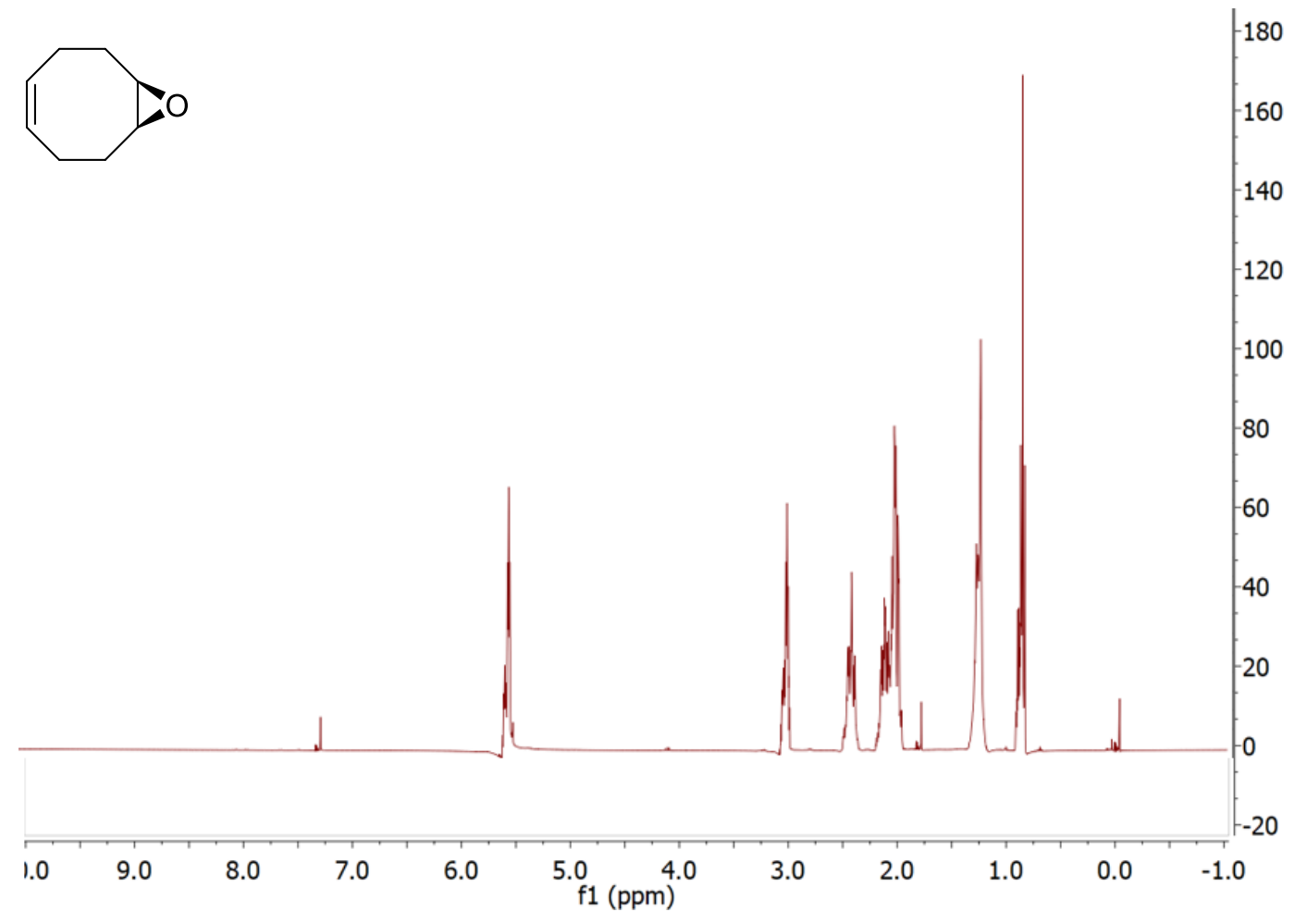

Figure S30. ${ }^{1} \mathrm{H}-\mathrm{NMR}$ spectrum of title compound. 
(Z)-cyclooct-4-en-1-ol (11)

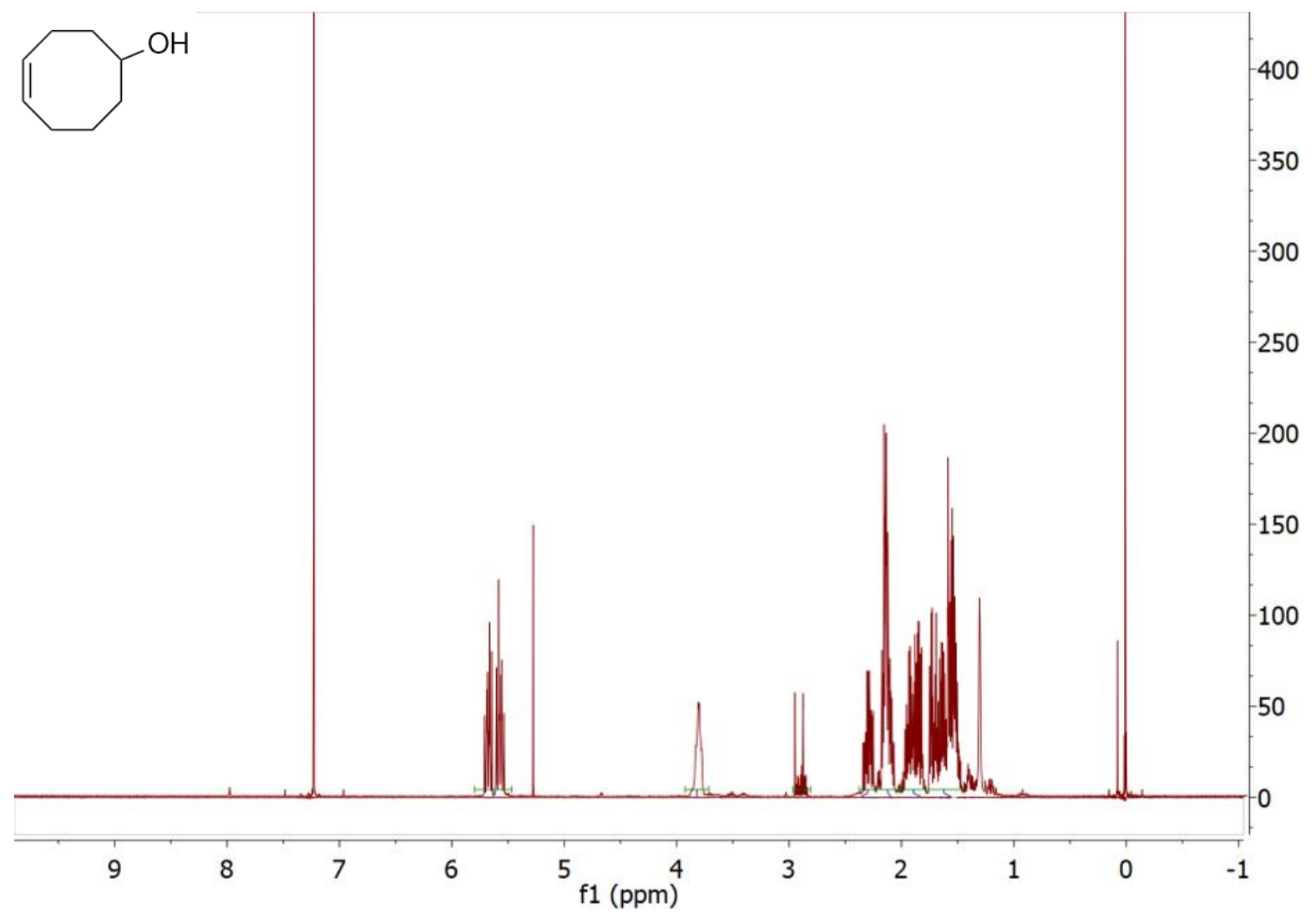

Figure S31. ${ }^{1} \mathrm{H}-\mathrm{NMR}$ spectrum of title compound. 
(Z)-cyclooct-4-enyl-acetate (12)

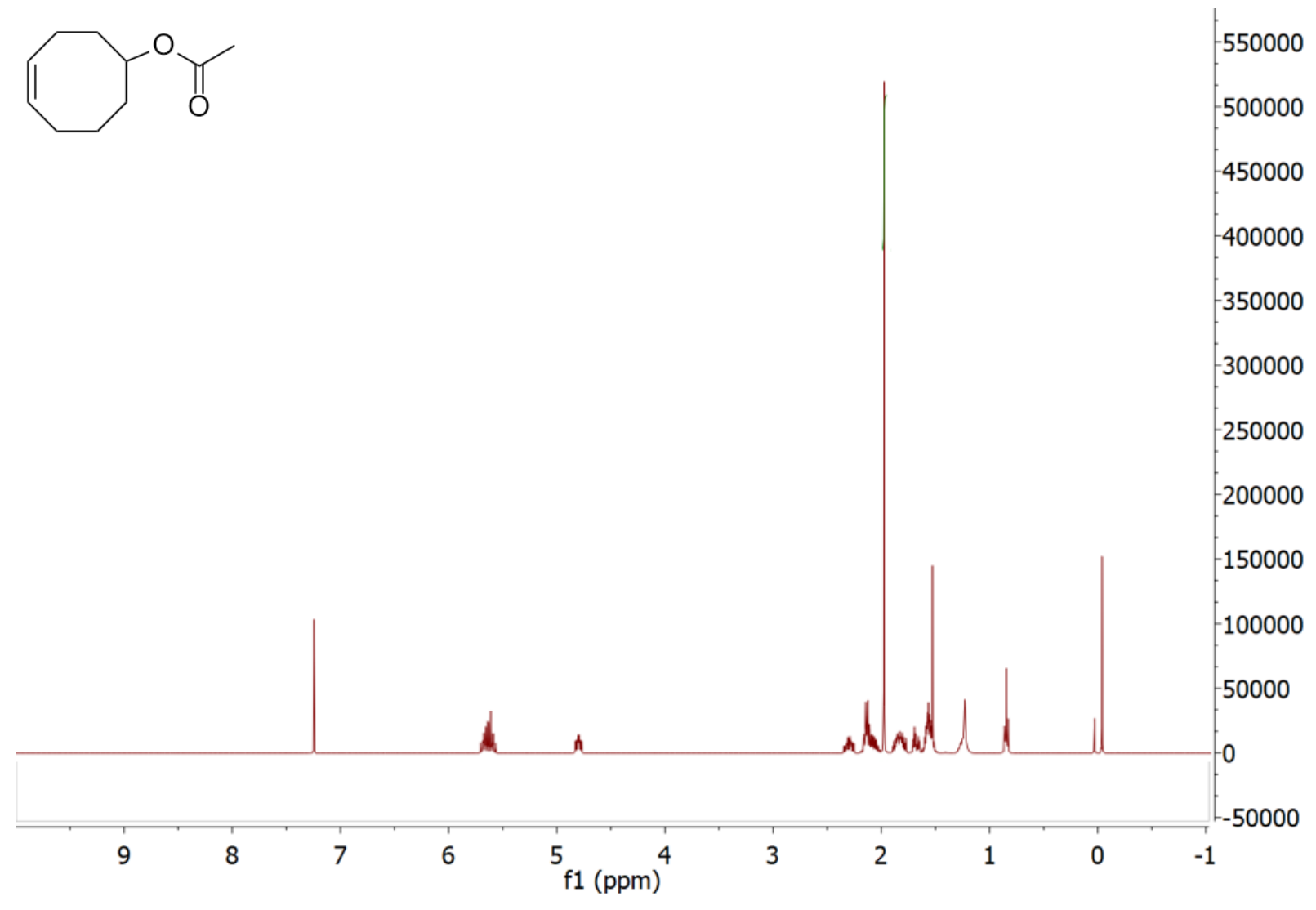

Figure S32. ${ }^{1} \mathrm{H}-\mathrm{NMR}$ spectrum of title compound. 
(E)-cyclooct-4-enyl-acetate (13)

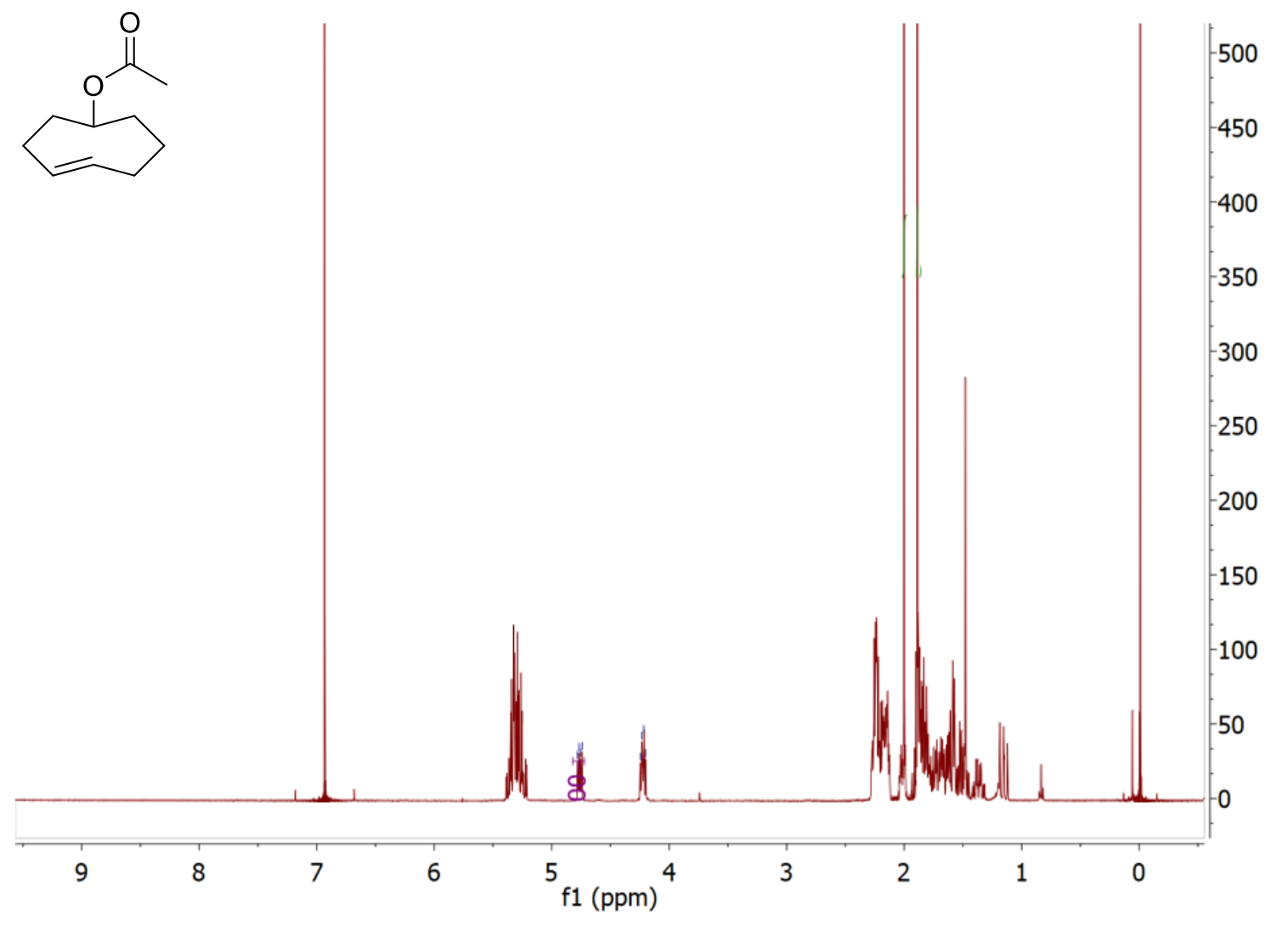

Figure S33. ${ }^{1} \mathrm{H}-\mathrm{NMR}$ spectrum of title compound. 
(E)-cyclooct-4-enol (14)

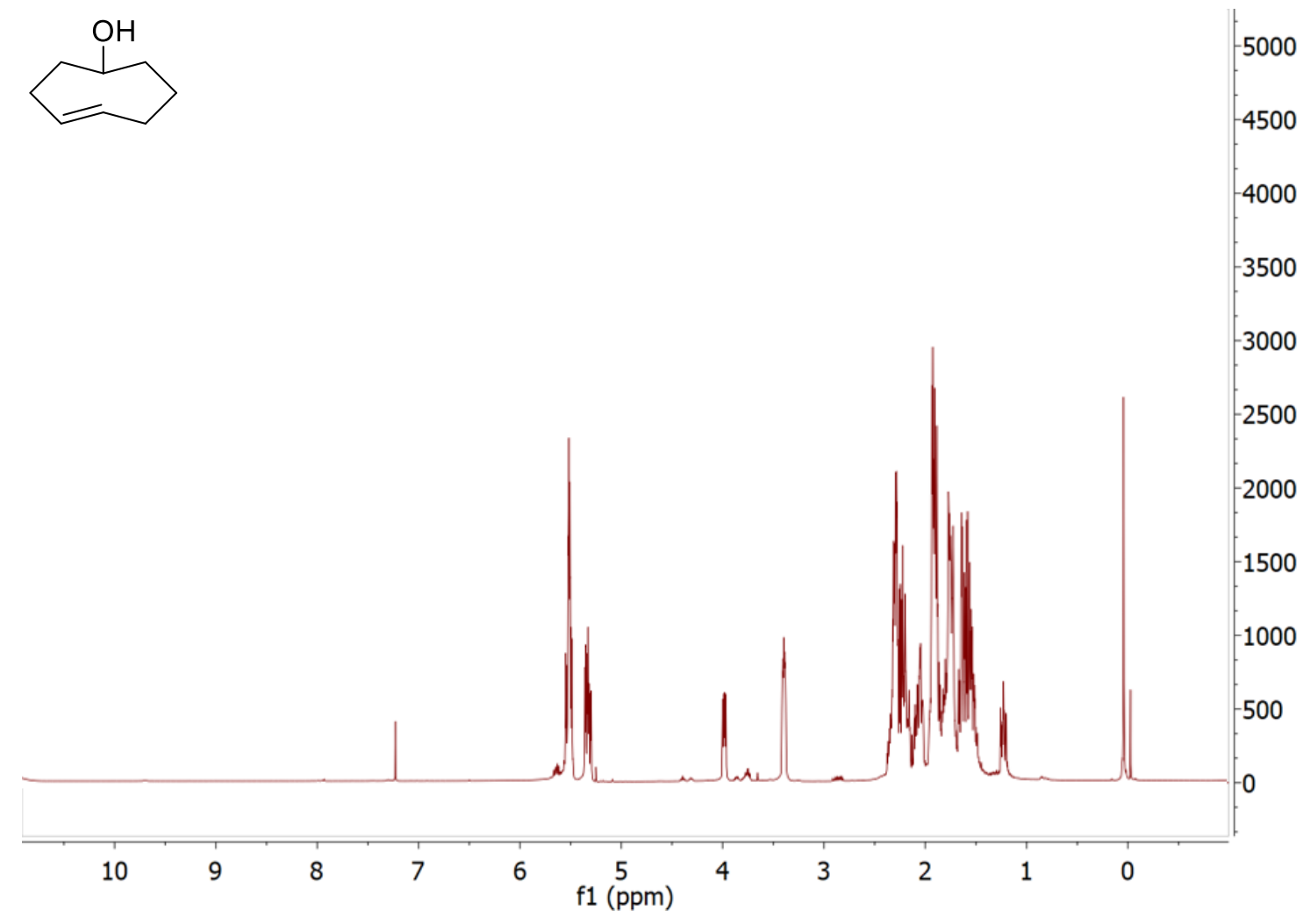

Figure S34. ${ }^{1} \mathrm{H}-\mathrm{NMR}$ spectrum of title compound. 
(E)-cyclooct-4-enyl-(4-nitrophenyl)carbonate (TCO) (15)

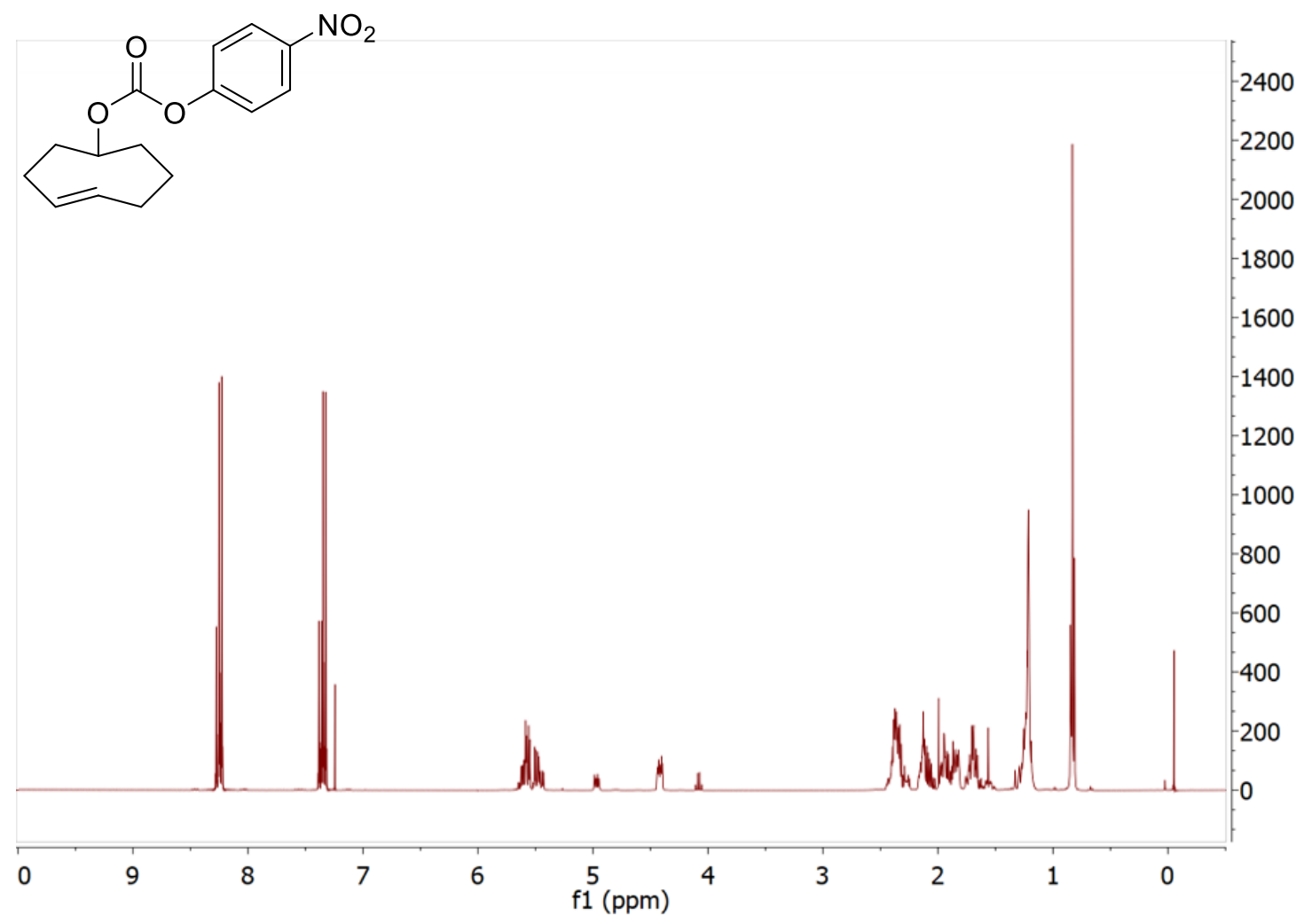

Figure S35. ${ }^{1} \mathrm{H}-\mathrm{NMR}$ spectrum of title compound. 
Star-PEG-TCO (17)

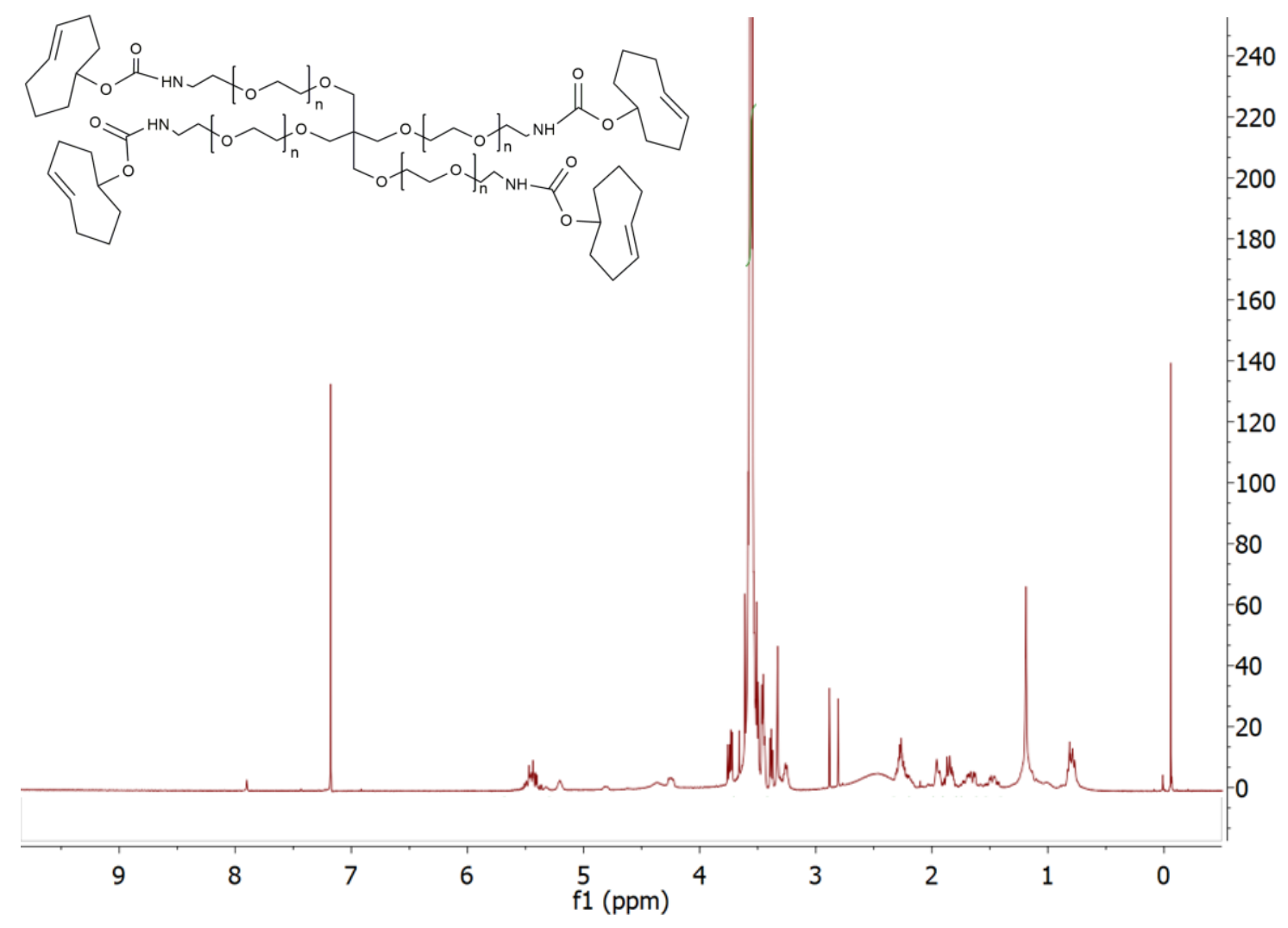

Figure S36. ${ }^{1} \mathrm{H}-\mathrm{NMR}$ spectrum of title compound. 


\section{Star-PEG-Tet (18)}

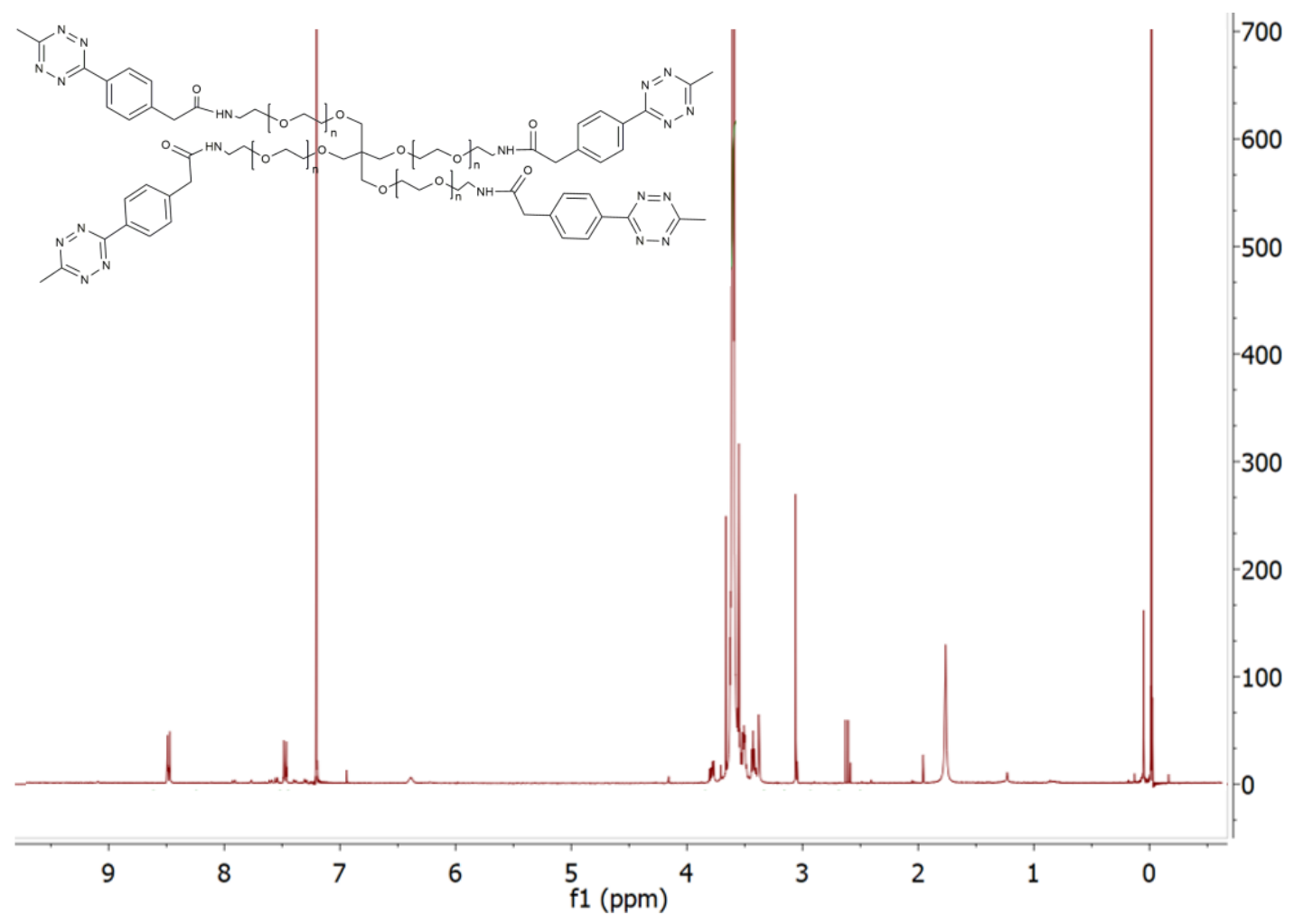

Figure S37. ${ }^{1} \mathrm{H}-\mathrm{NMR}$ spectrum of title compound. 
Star-PEG-BCN (19)

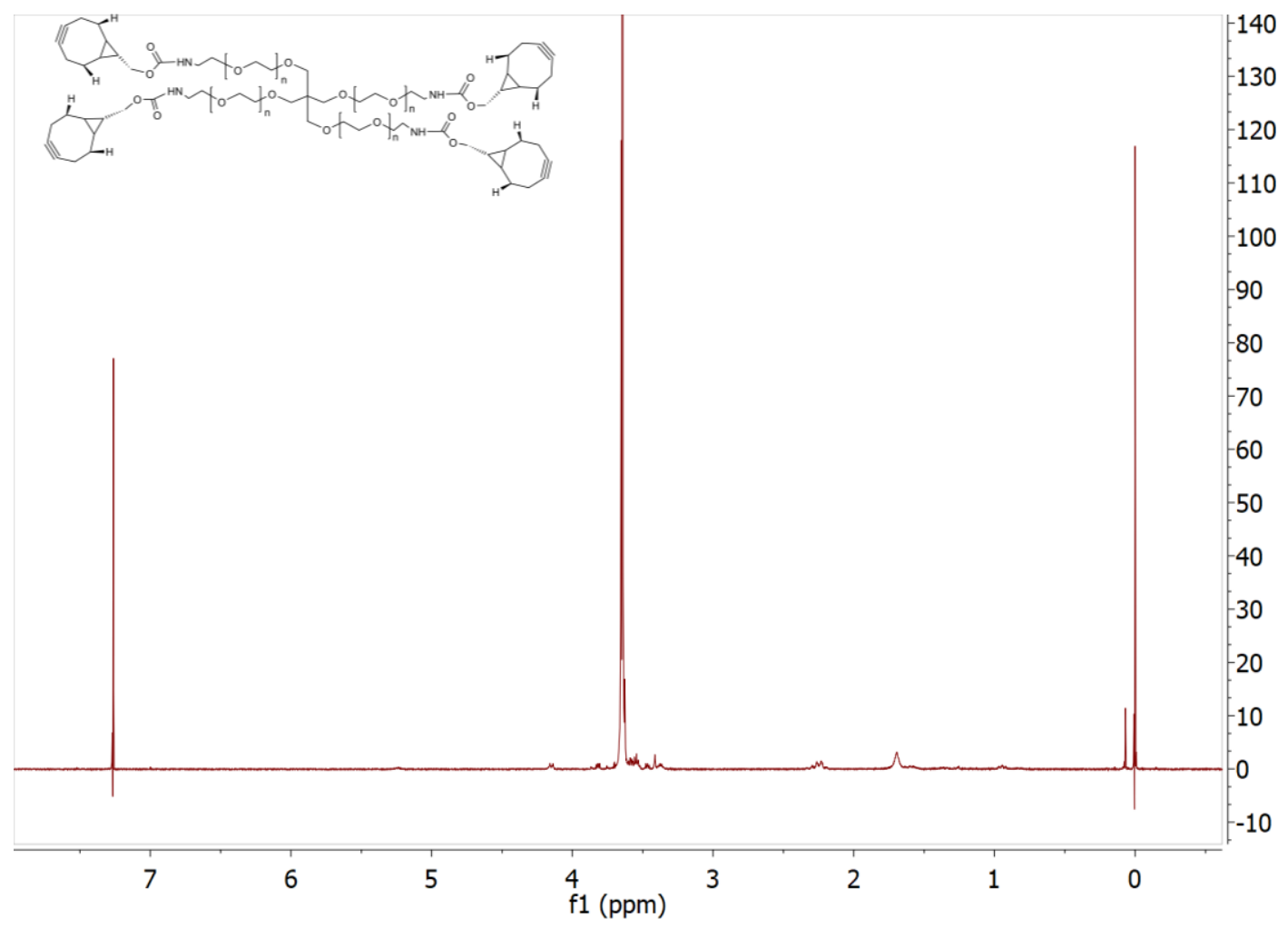

Figure S38. ${ }^{1} \mathrm{H}-\mathrm{NMR}$ spectrum of title compound. 
Star-PEG-DHPA (20)

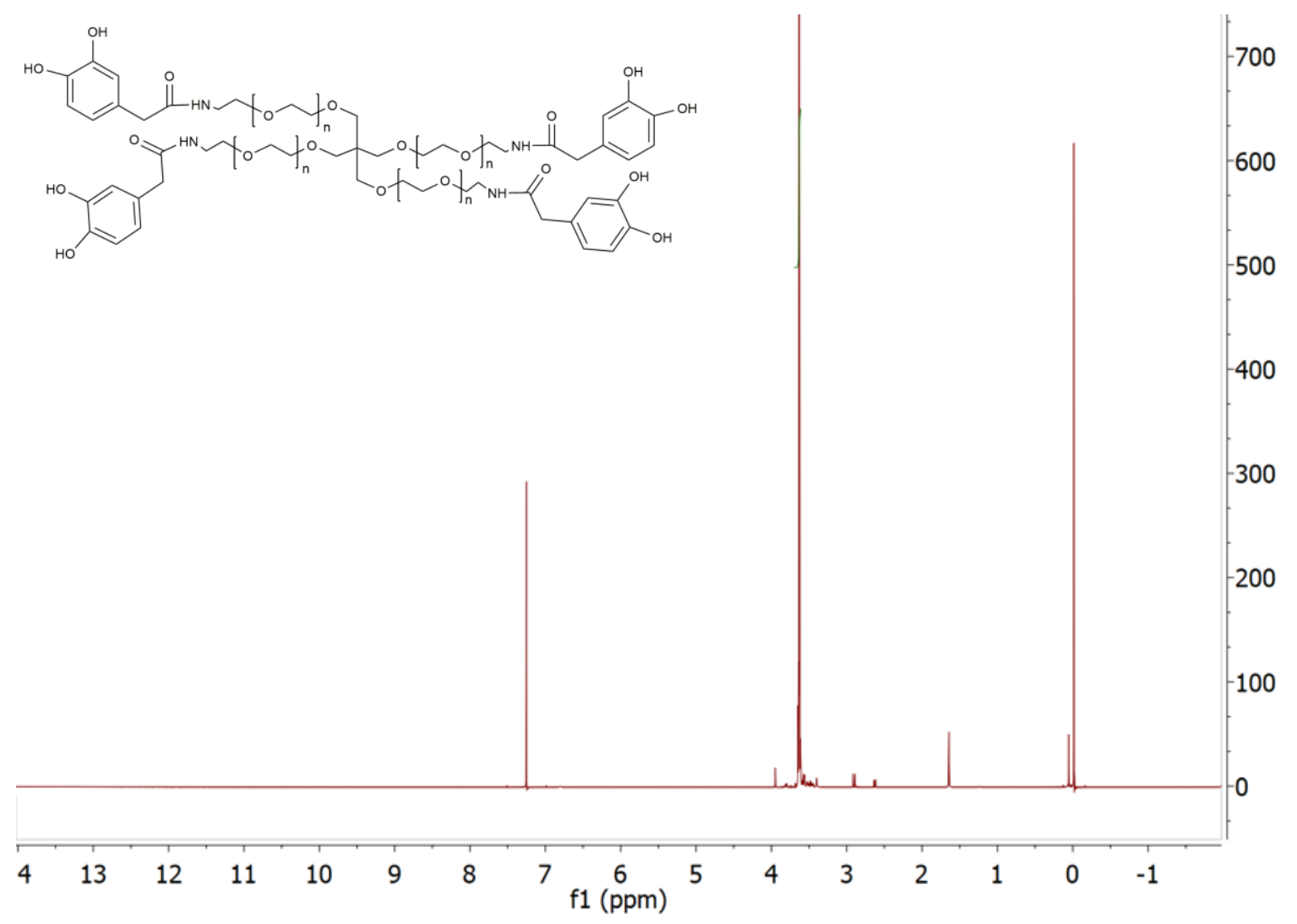

Figure S39. ${ }^{1} \mathrm{H}-\mathrm{NMR}$ spectrum of title compound. 
Star-PEG-DBCO (21)

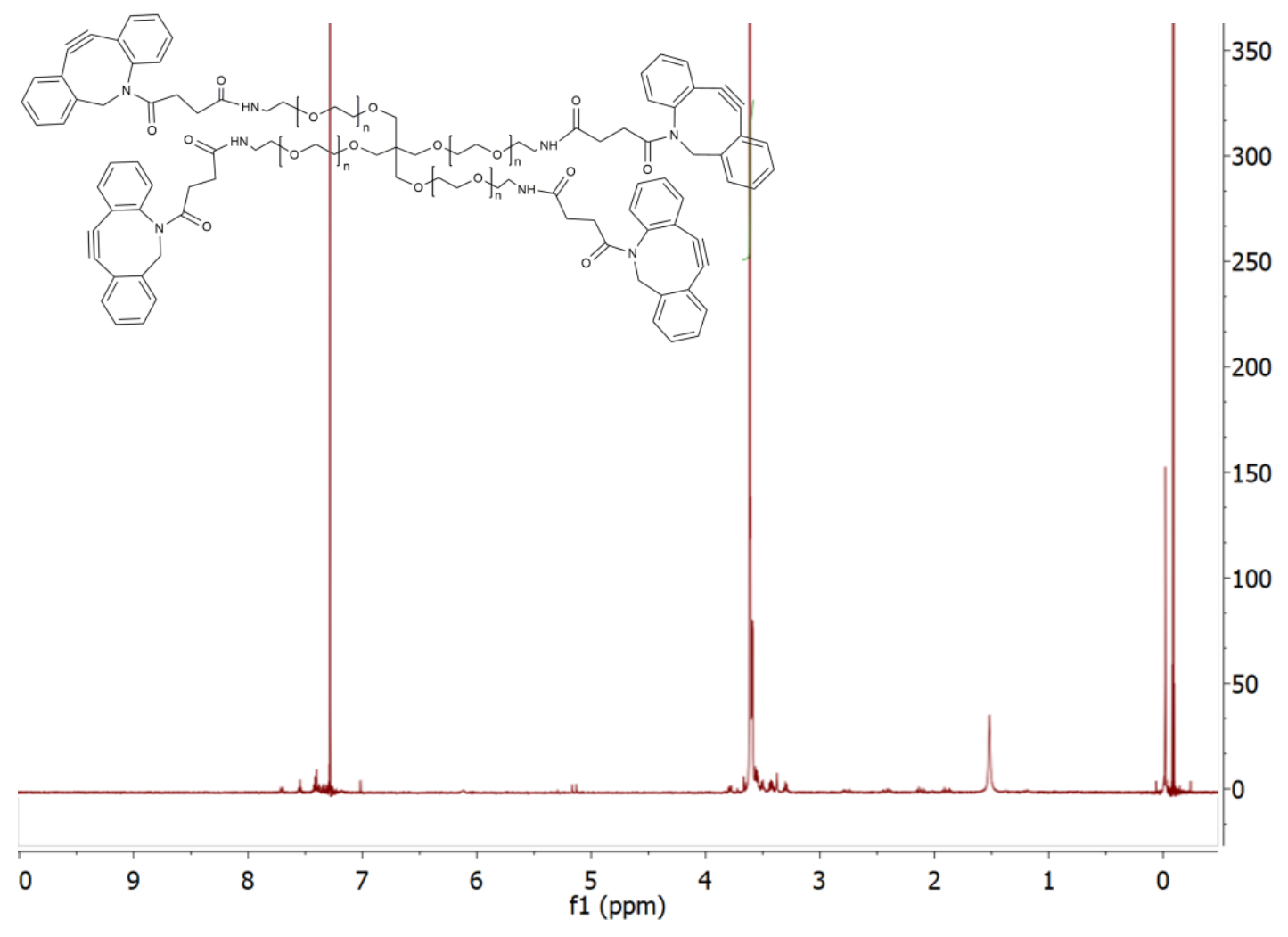

Figure S40. ${ }^{1} \mathrm{H}-\mathrm{NMR}$ spectrum of title compound. 


\section{Star-PEG-N $3(22)$}

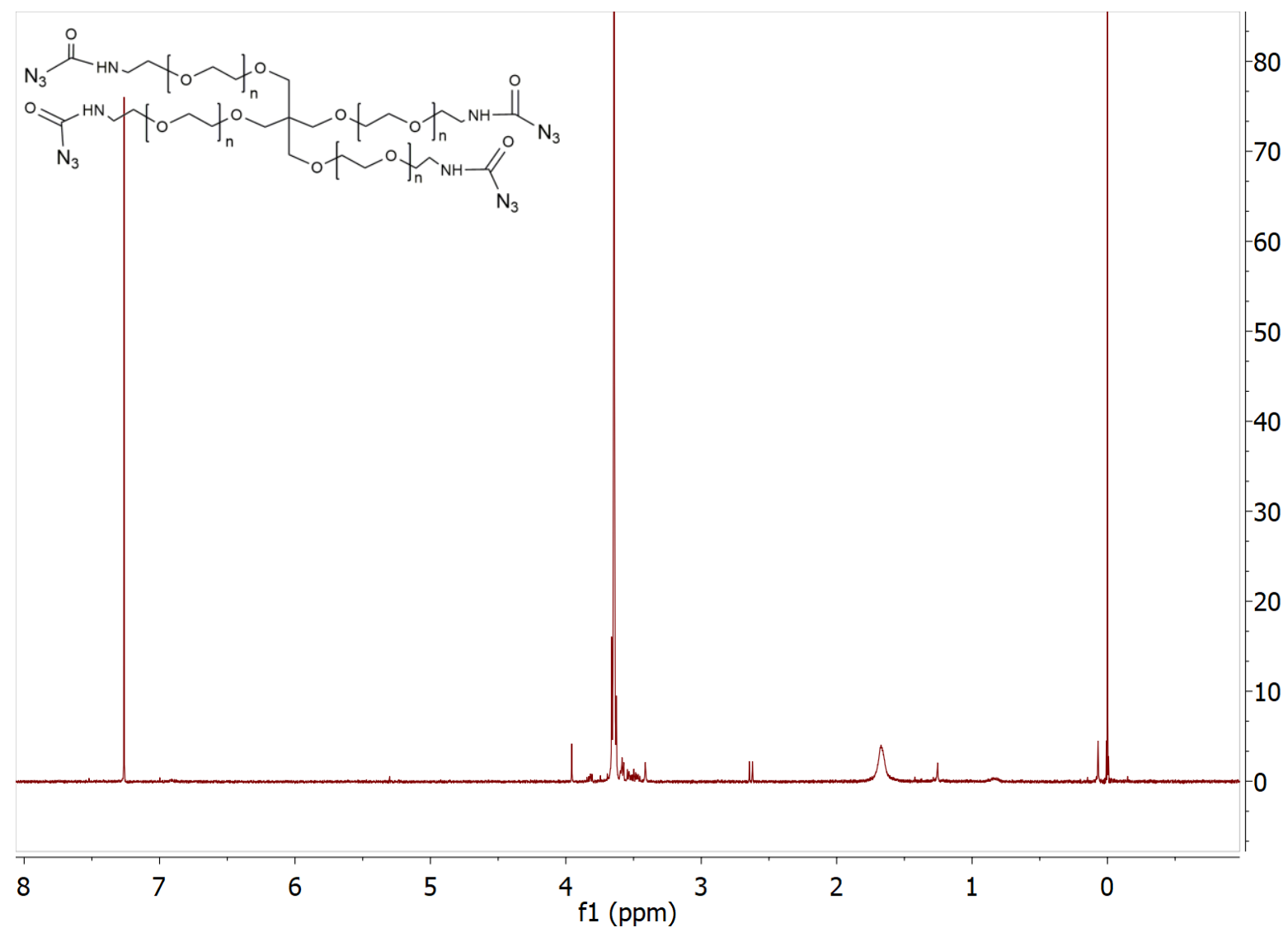

Figure S41. ${ }^{1} \mathrm{H}-\mathrm{NMR}$ spectrum of title compound. 
Star-PEG-Norb (23)

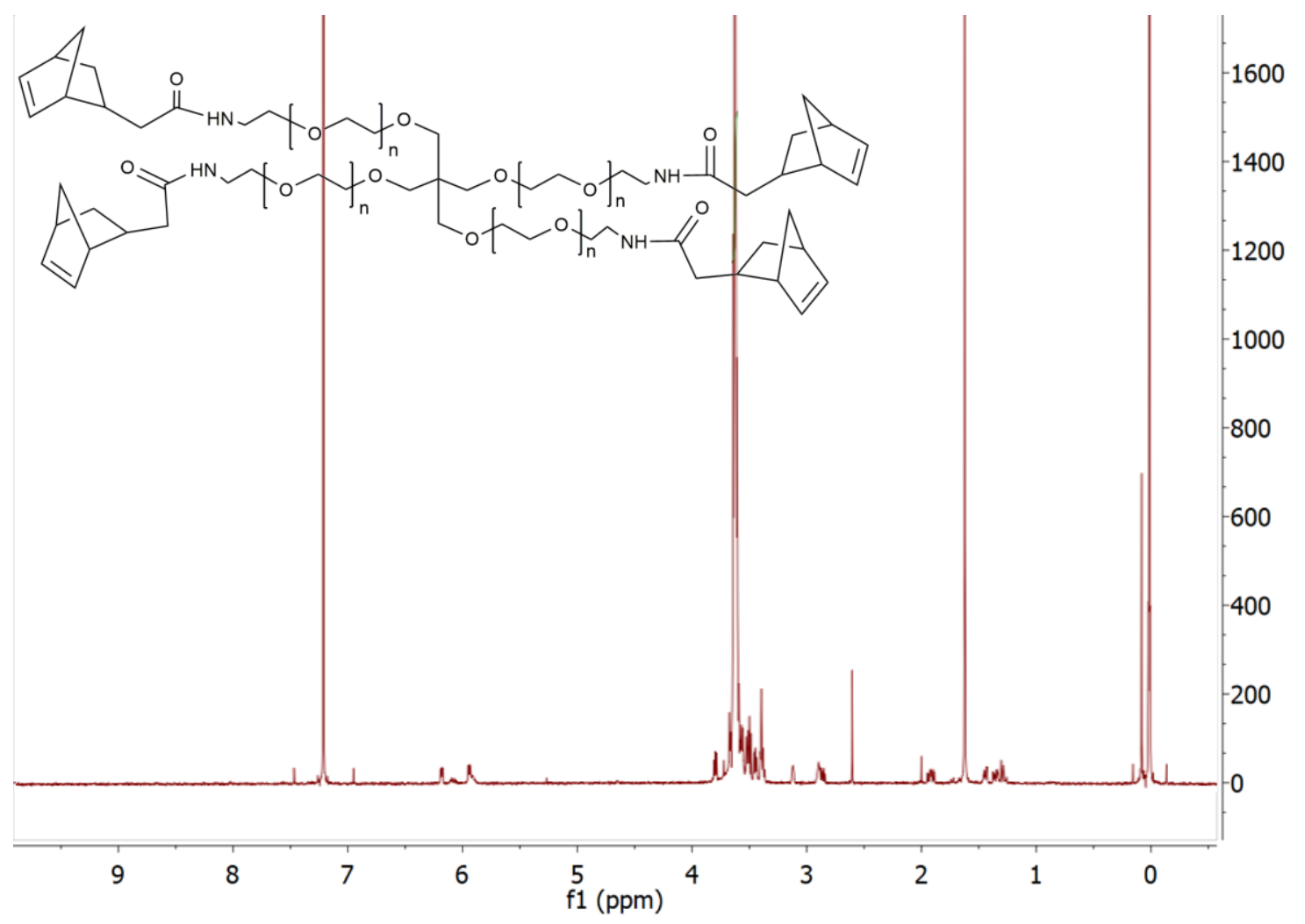

Figure S42. ${ }^{1} \mathrm{H}-\mathrm{NMR}$ spectrum of title compound. 
Star-PEG-MMPcp- $\mathrm{N}_{3}(24)$

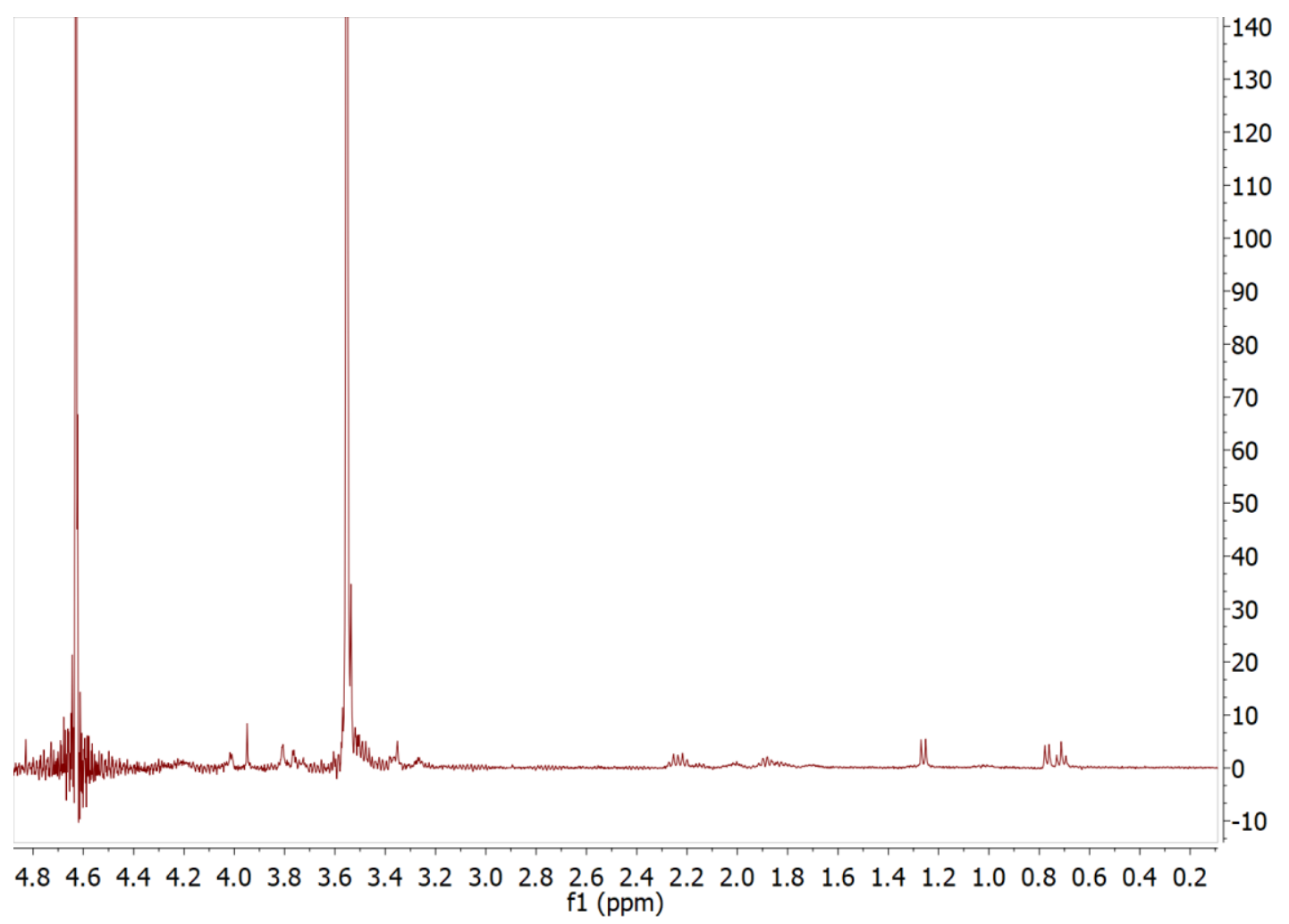

Figure S43. ${ }^{1} \mathrm{H}-\mathrm{NMR}$ spectrum of title compound. 
Star-PEG-SDGR-N $\mathrm{N}_{3}$ (25) (in methnol)

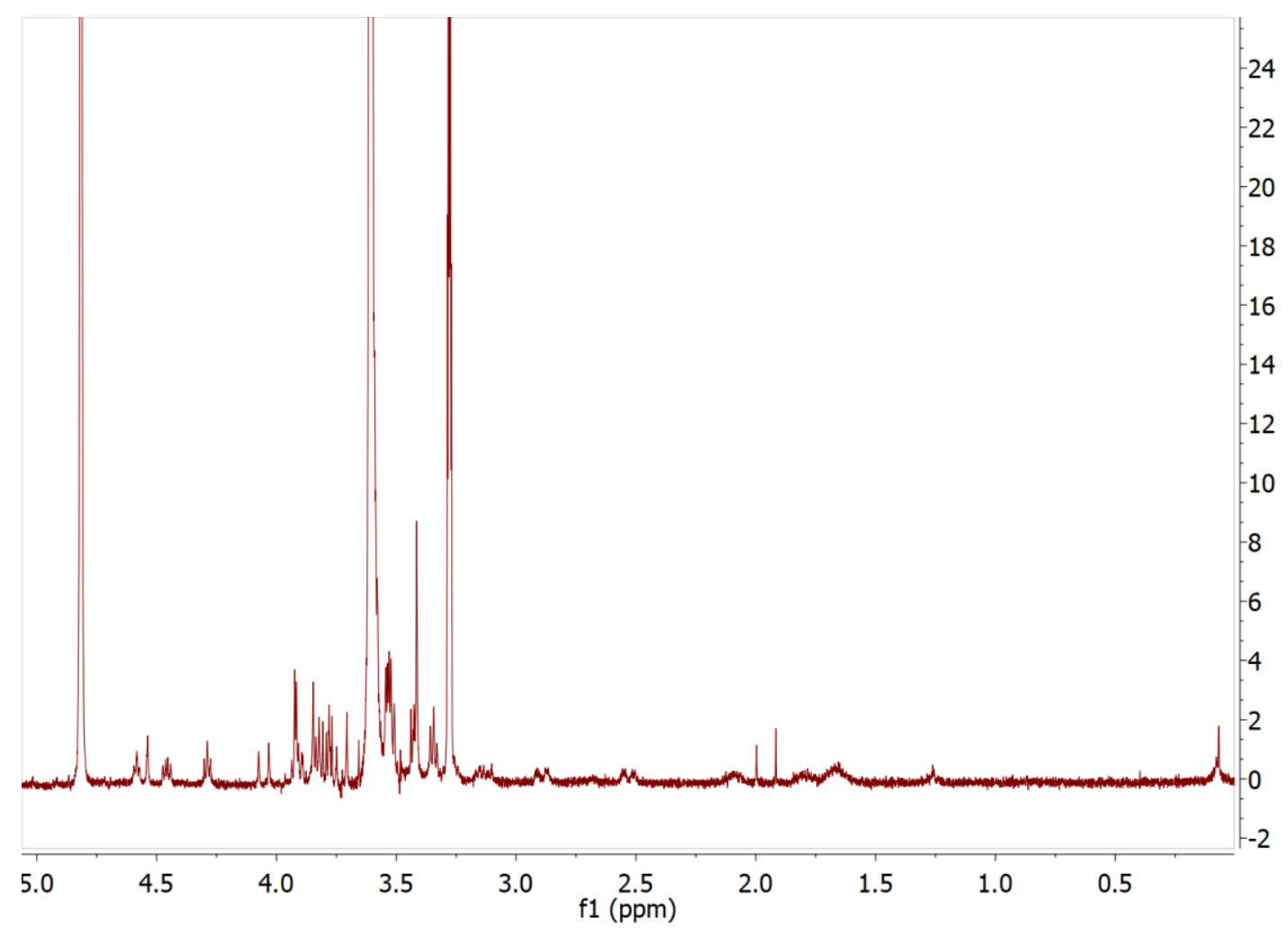

Figure S44. ${ }^{1} \mathrm{H}-\mathrm{NMR}$ spectrum of title compound. 
(F) Appendix 4. Cryo-SEM images of PEG based hydrogels

\section{TCO/Tet}

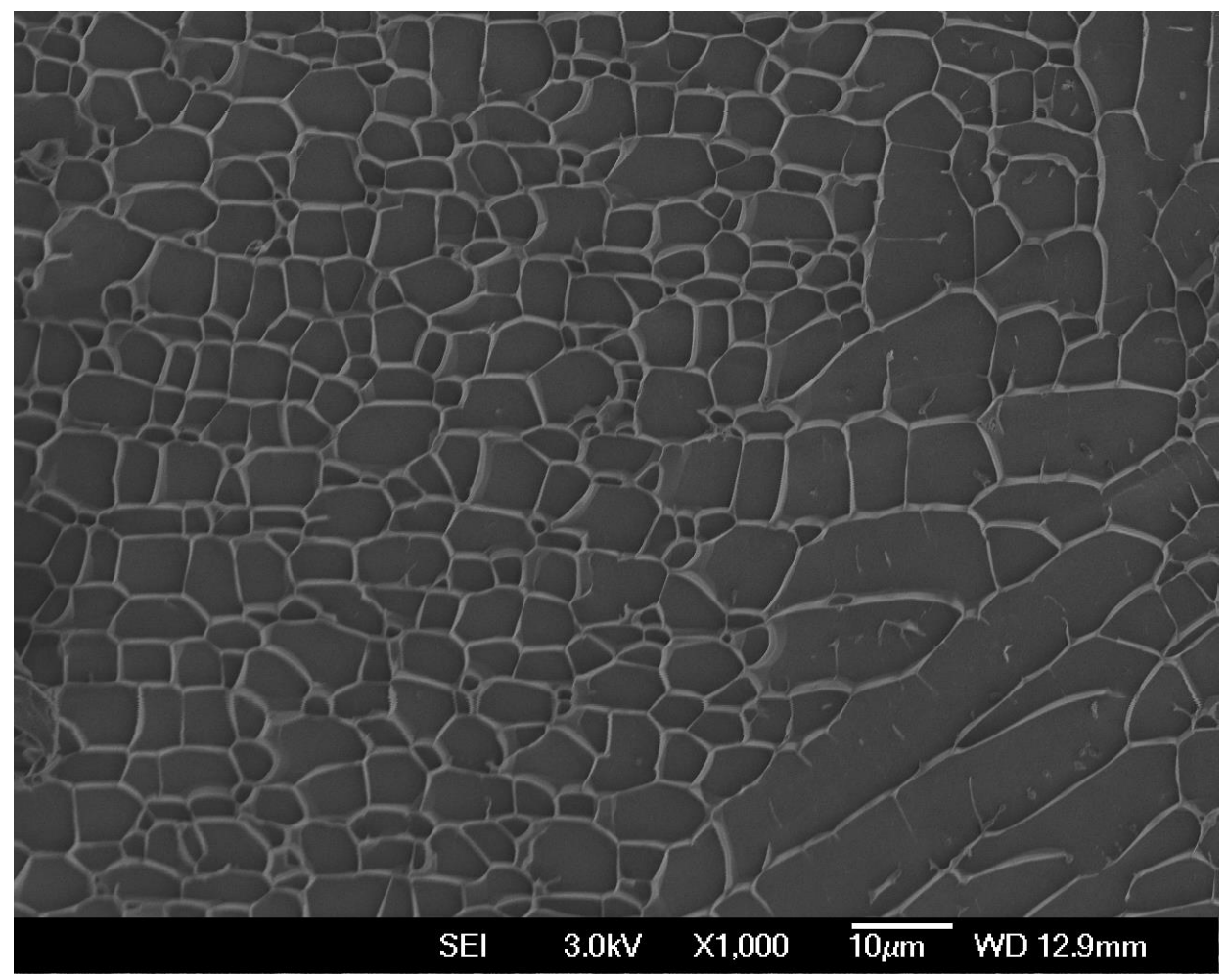

Figure S45. Cryo-SEM image of title compound. 
BCN/DHPA

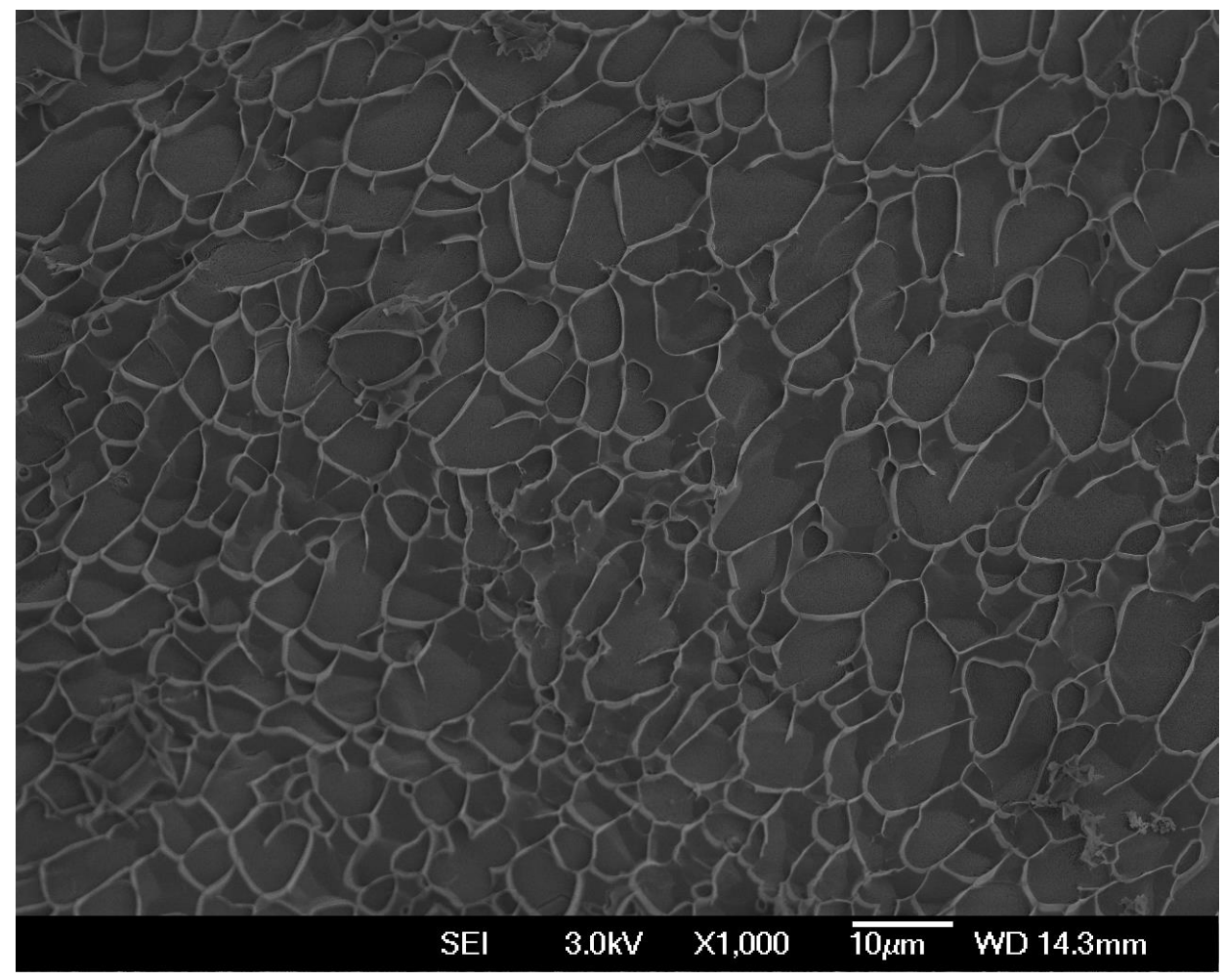

Figure S46. Cryo-SEM image of title compound. 
BCN/Tet

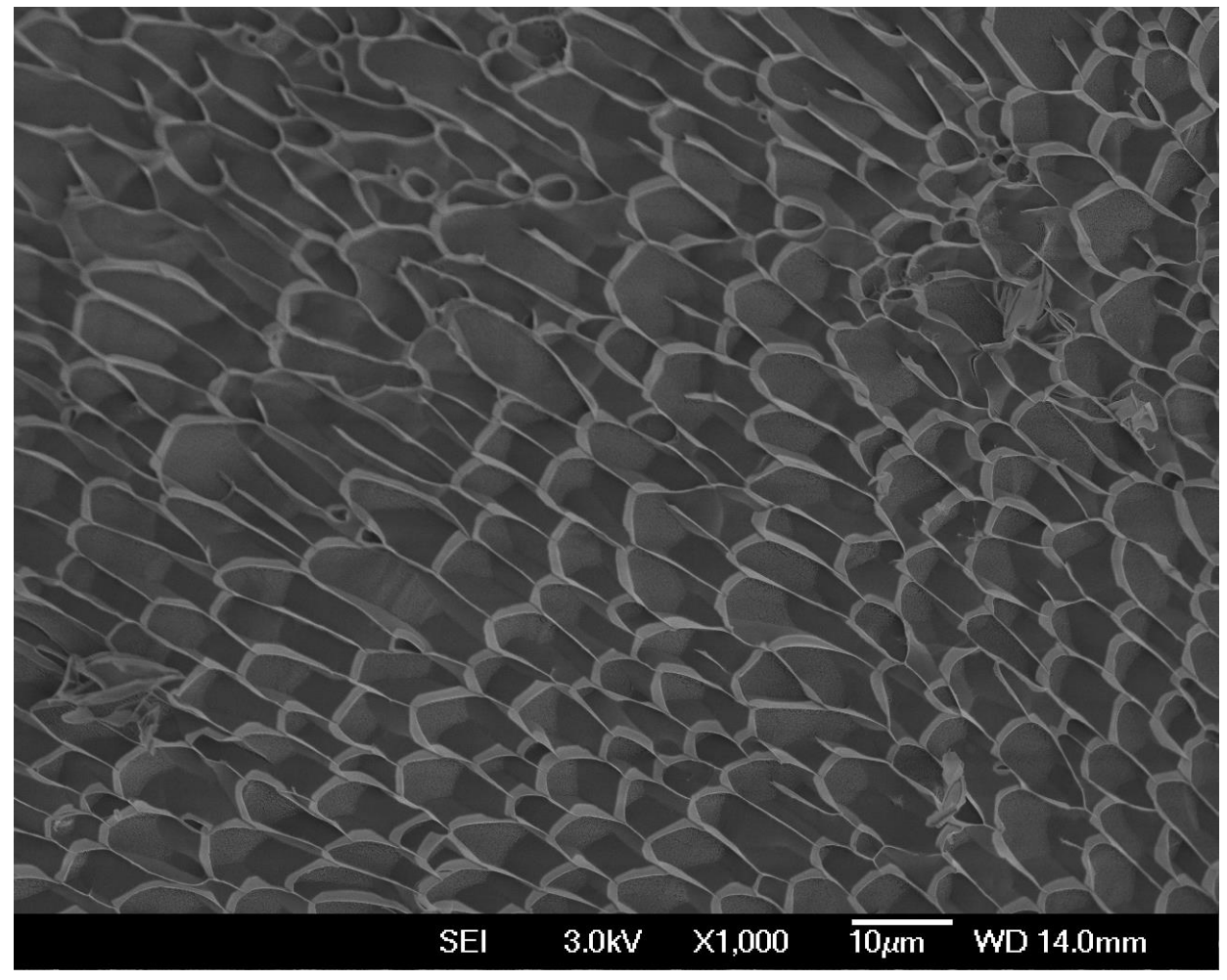

Figure S47. Cryo-SEM image of title compound. 
DBCO/DHPA

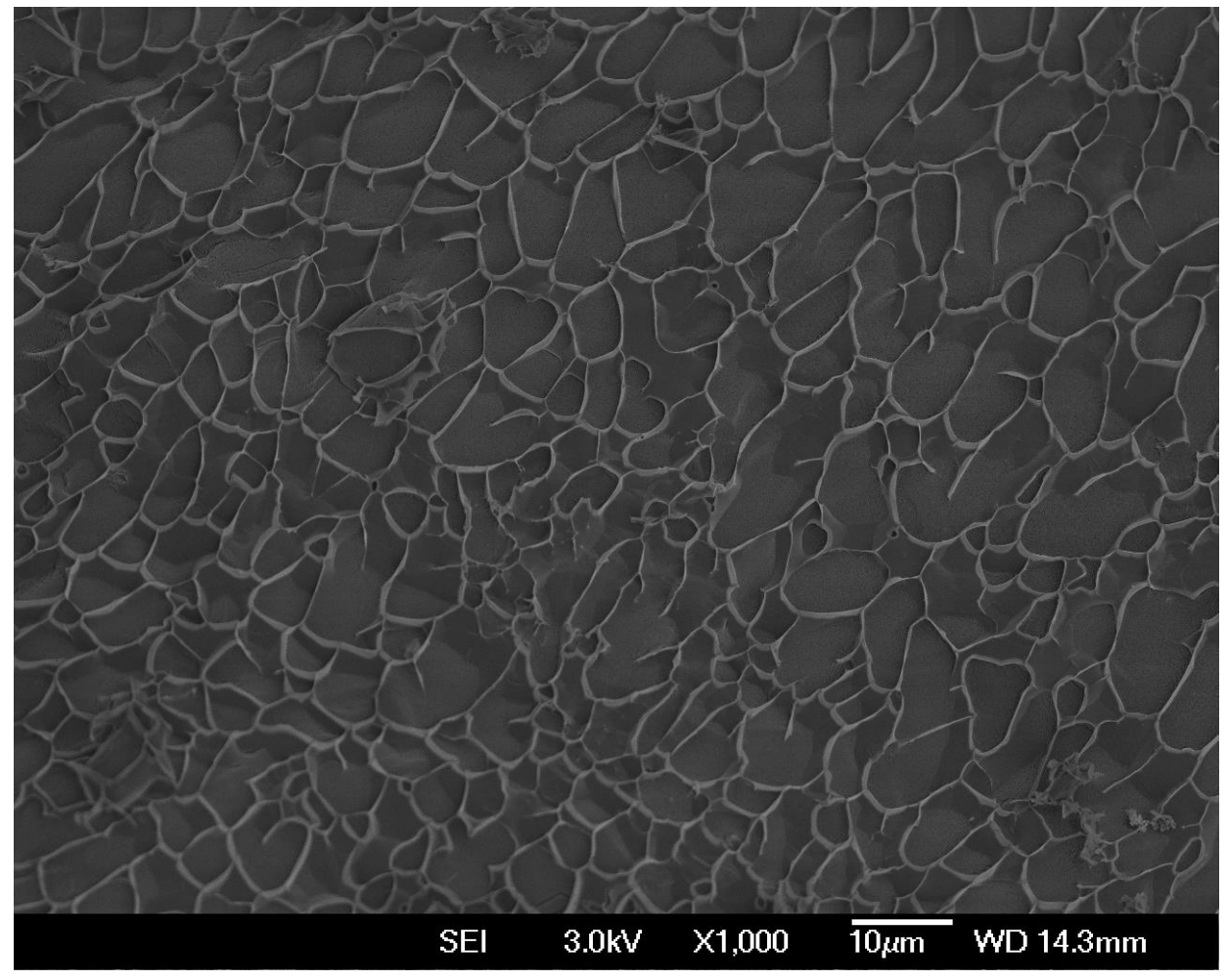

Figure S48. Cryo-SEM image of title compound. 
$\mathrm{DBCO} / \mathrm{N}_{3}$

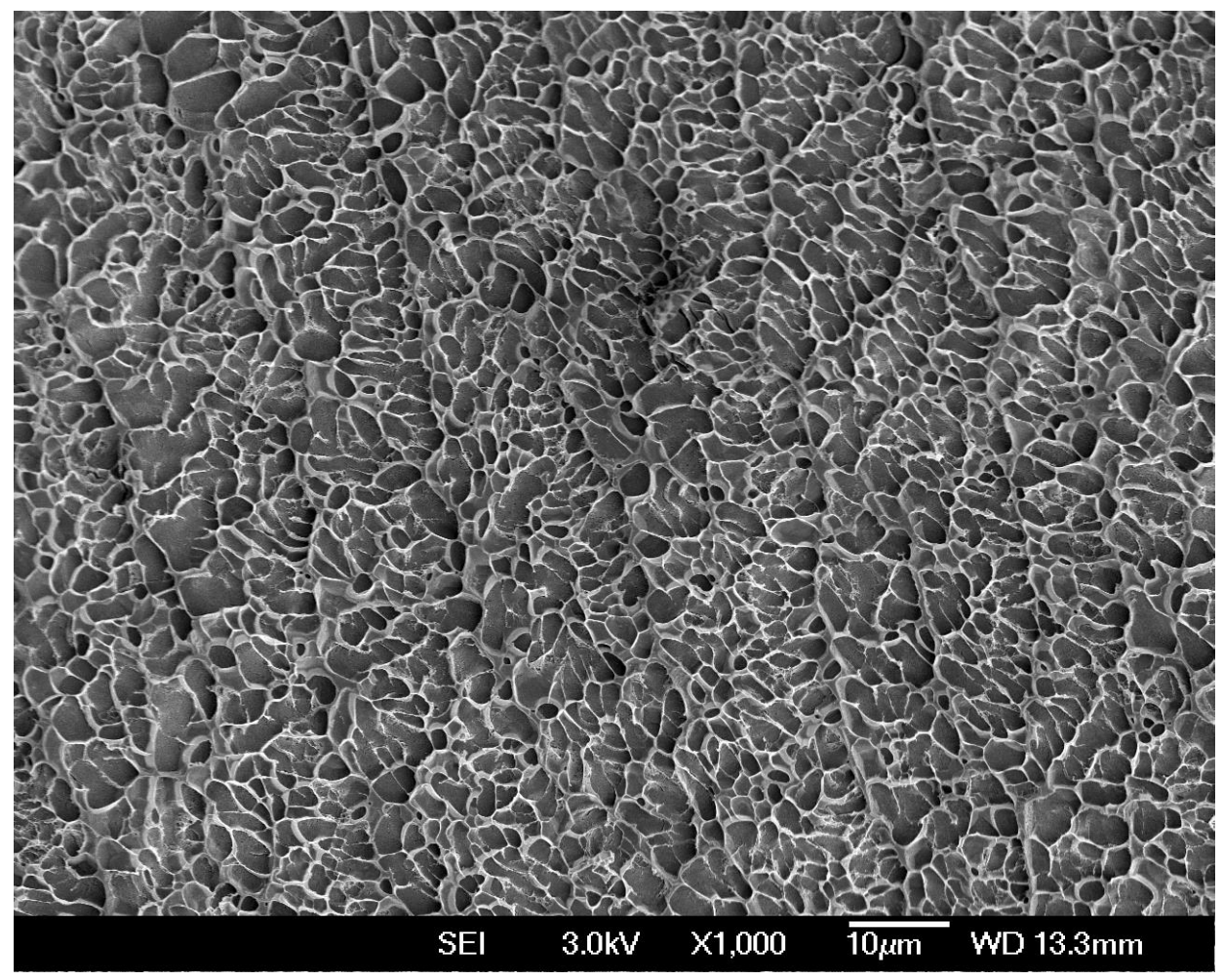

Figure S49. Cryo-SEM image of title compound. 
$\mathrm{BCN} / \mathrm{N}_{3}$

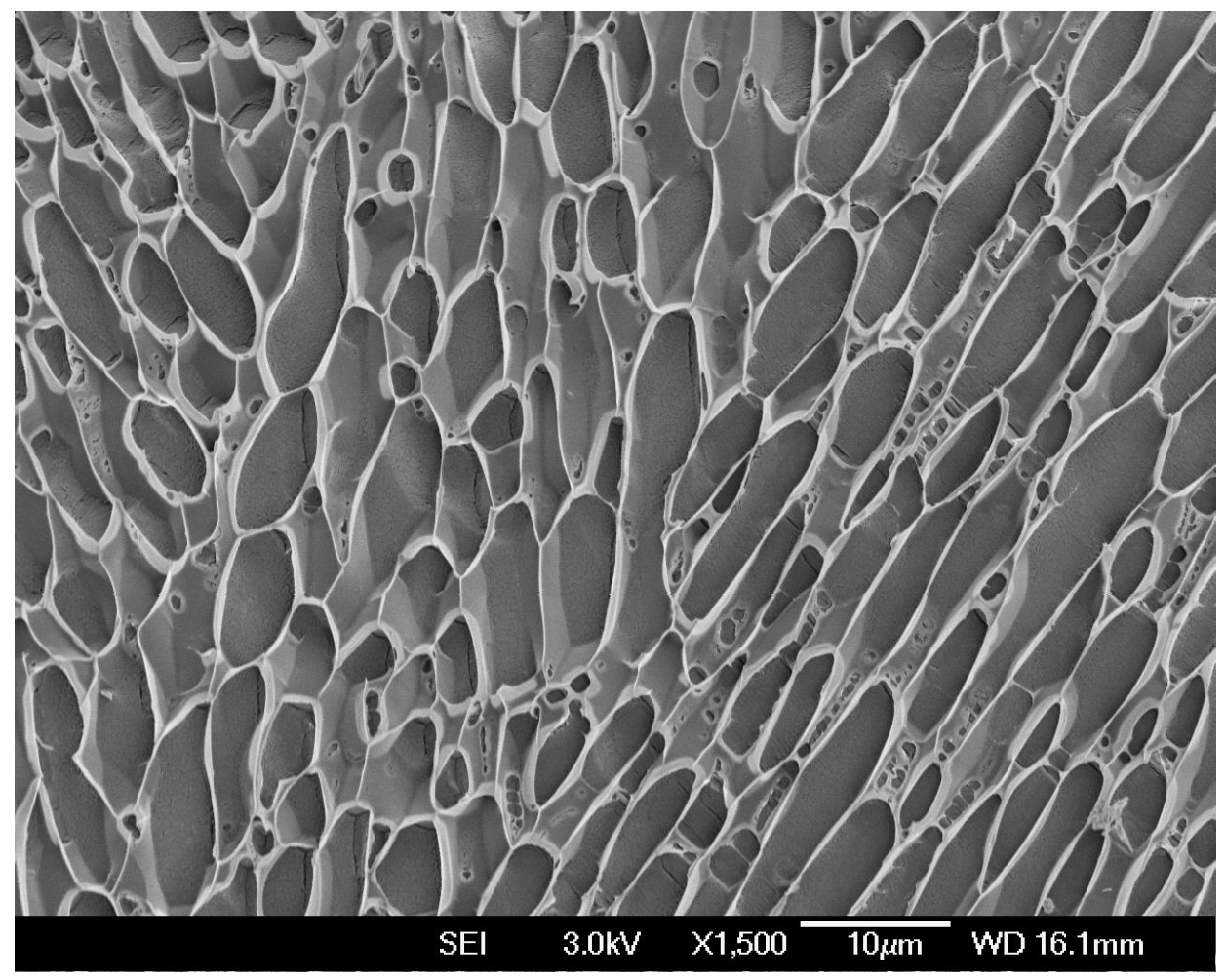

Figure S50. Cryo-SEM image of title compound. 


\section{Norb/Tet}

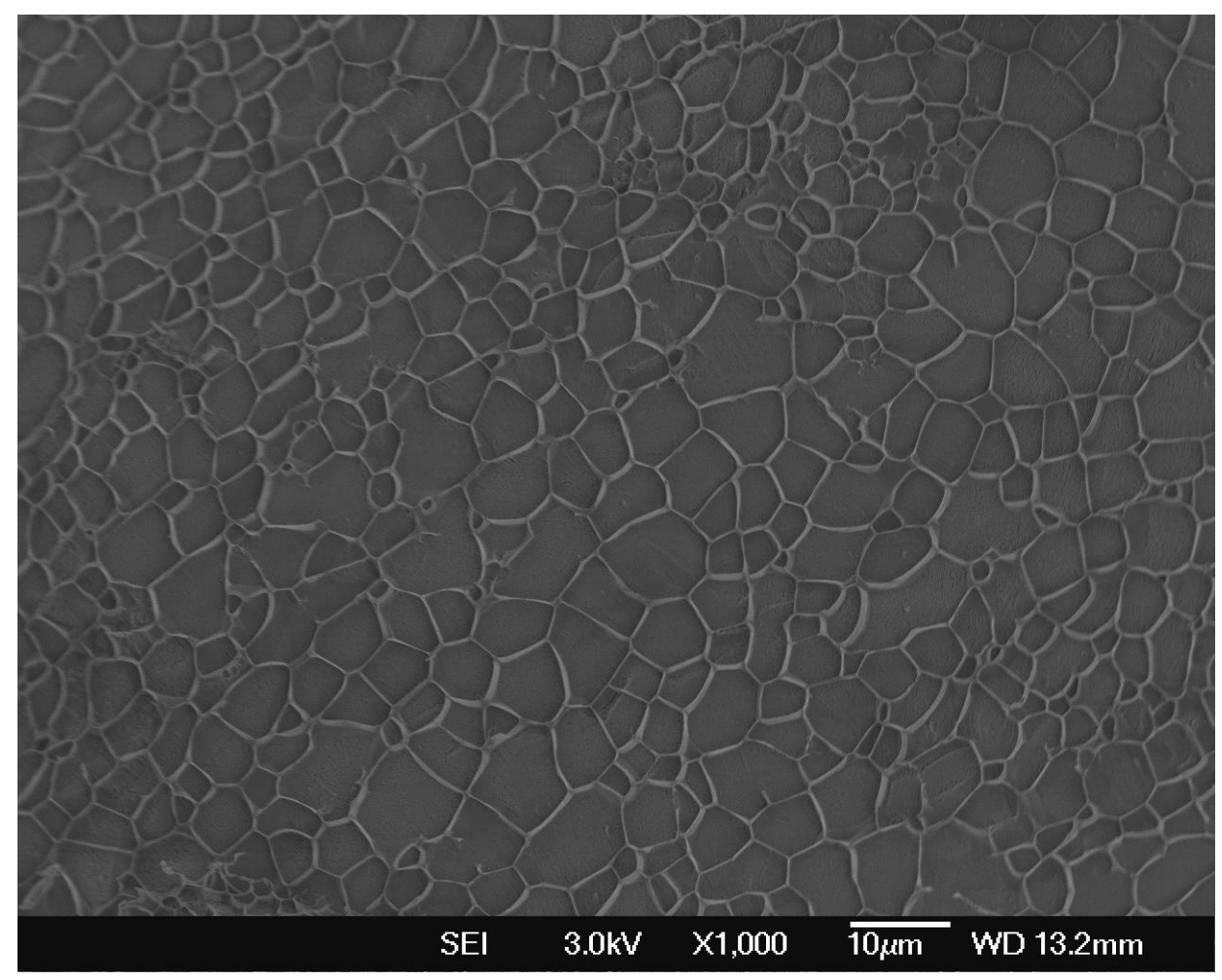

Figure S51. Cryo-SEM image of title compound. 